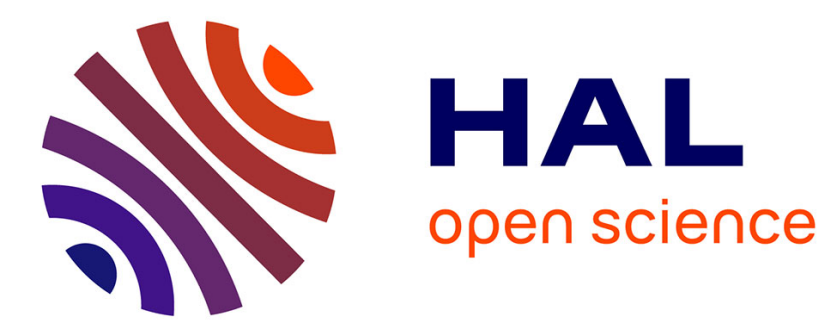

\title{
A meta-analysis of the effects of nutrient enrichment on litter decomposition in streams
}

Veronica Ferreira, Bastien Castagneyrol, Julia Koricheva, Vladislav Gulis, Eric Chauvet, Manuel A. S. Graça

\section{- To cite this version:}

Veronica Ferreira, Bastien Castagneyrol, Julia Koricheva, Vladislav Gulis, Eric Chauvet, et al.. A meta-analysis of the effects of nutrient enrichment on litter decomposition in streams. Biological Reviews, 2015, vol. 90 ( $\mathrm{n}^{\circ} 3$ ), pp. 669-688. 10.1111/brv.12125 . hal-01186536

\section{HAL Id: hal-01186536 \\ https://hal.science/hal-01186536}

Submitted on 25 Aug 2015

HAL is a multi-disciplinary open access archive for the deposit and dissemination of scientific research documents, whether they are published or not. The documents may come from teaching and research institutions in France or abroad, or from public or private research centers.
L'archive ouverte pluridisciplinaire HAL, est destinée au dépôt et à la diffusion de documents scientifiques de niveau recherche, publiés ou non, émanant des établissements d'enseignement et de recherche français ou étrangers, des laboratoires publics ou privés. 


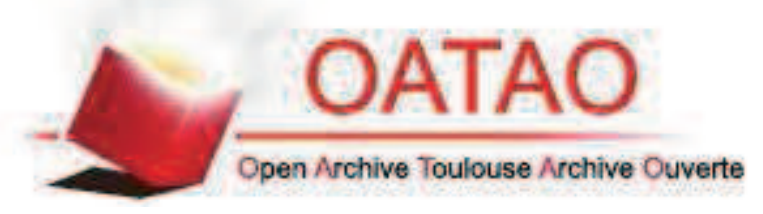

\section{Open Archive TOULOUSE Archive Ouverte (OATAO)}

OATAO is an open access repository that collects the work of Toulouse researchers and makes it freely available over the web where possible.

This is an author-deposited version published in : http://oatao.univ-toulouse.fr/ Eprints ID : 13702

To link to this article : doi: $10.1111 /$ brv. 12125

URL : http://dx.doi.org/10.1111/brv.12125

To cite this version : Ferreira, Veronica and Castagneyrol, Bastien and Koricheva, Julia and Gulis, Vladislav and Chauvet, Eric and Graça, Manuel A. S. A meta-analysis of the effects of nutrient enrichment on litter decomposition in streams. (2014) Biological Reviews. ISSN $1464-7931$

Any correspondance concerning this service should be sent to the repository administrator: staff-oatao@listes-diff.inp-toulouse.fr 


\title{
A meta-analysis of the effects of nutrient enrichment on litter decomposition in streams
}

\author{
Verónica Ferreira $^{1, *}$, Bastien Castagneyrol ${ }^{2,3,4}$, Julia Koricheva ${ }^{2}$, Vladislav Gulis ${ }^{5}$, \\ Eric Chauvet ${ }^{6,7}$ and Manuel A. S. Graça ${ }^{1}$ \\ ${ }^{1}$ IMAR-CMA, Department of Life Sciences, University of Coimbra, PO Box 3046, 3001-401, Coimbra, Portugal \\ ${ }^{2}$ School of Biological Sciences, Royal Holloway University of London, Egham, Surrey TW200EX, U.K. \\ ${ }^{3}$ Univ Bordeaux, UMR1202, BIOGECO, F-33400 Talence, France \\ ${ }^{4}$ INRA, UMR1202, BIOGECO, F-33610 Cestas, France \\ ${ }^{5}$ Department of Biology, Coastal Carolina University, PO Box 261954 Conway, SC 29528-6054, U.S.A. \\ ${ }^{6}$ UPS, INPT, EcoLab (Laboratoire Ecologie Fonctionnelle et Environnement), Université de Toulouse, 31062 Toulouse, France \\ ${ }^{7}$ CNRS, EcoLab, 31062 Toulouse, France
}

\begin{abstract}
The trophic state of many streams is likely to deteriorate in the future due to the continuing increase in human-induced nutrient availability. Therefore, it is of fundamental importance to understand how nutrient enrichment affects plant litter decomposition, a key ecosystem-level process in forest streams. Here, we present a meta-analysis of 99 studies published between 1970 and 2012 that reported the effects of nutrient enrichment on litter decomposition in running waters. When considering the entire database, which consisted of 840 case studies, nutrient enrichment stimulated litter decomposition rate by approximately $50 \%$. The stimulation was higher when the background nutrient concentrations were low and the magnitude of the nutrient enrichment was high, suggesting that oligotrophic streams are most vulnerable to nutrient enrichment. The magnitude of the nutrient-enrichment effect on litter decomposition was higher in the laboratory than in the field experiments, suggesting that laboratory experiments overestimate the effect and their results should be interpreted with caution. Among field experiments, effects of nutrient enrichment were smaller in the correlative than in the manipulative experiments since in the former the effects of nutrient enrichment on litter decomposition were likely confounded by other environmental factors, e.g. pollutants other than nutrients commonly found in streams impacted by human activity. However, primary studies addressing the effect of multiple stressors on litter decomposition are still few and thus it was not possible to consider the interaction between factors in this review. In field manipulative experiments, the effect of nutrient enrichment on litter decomposition depended on the scale at which the nutrients were added: stream reach $>$ streamside channel $>$ litter bag. This may have resulted from a more uniform and continuous exposure of microbes and detritivores to nutrient enrichment at the stream-reach scale. By contrast, nutrient enrichment at the litter-bag scale, often by using diffusing substrates, does not provide uniform controllable nutrient release at either temporal or spatial scales, suggesting that this approach should be abandoned. In field manipulative experiments, the addition of both nitrogen $(\mathrm{N})$ and phosphorus $(\mathrm{P})$ resulted in stronger stimulation of litter decomposition than the addition of $\mathrm{N}$ or $\mathrm{P}$ alone, suggesting that there might be nutrient co-limitation of decomposition in streams. The magnitude of the nutrient-enrichment effect on litter decomposition was higher for wood than for leaves, and for low-quality than for high-quality leaves. The effect of nutrient enrichment on litter decomposition may also depend on climate. The tendency for larger effect size in colder regions suggests that patterns of biogeography of invertebrate decomposers may be modulating the effect of nutrient enrichment on litter decomposition. Although studies in temperate environments were overrepresented in our database, our meta-analysis suggests that the effect of nutrient enrichment might be strongest in cold oligotrophic streams that depend on low-quality plant litter inputs.
\end{abstract}

* Address for correspondence (Tel: +351 239837 797; Fax: +351 239823 603; E-mail: veronica@ci.uc.pt). 
Key words: climate, decomposers, detritivores, fungi, litter processing, nutrient addition, inorganic nutrients, eutrophication, experimental setting, plant litter.

\section{CONTENTS}

I. Introduction

II. Methods

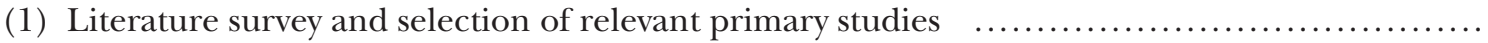

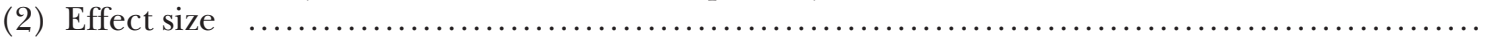

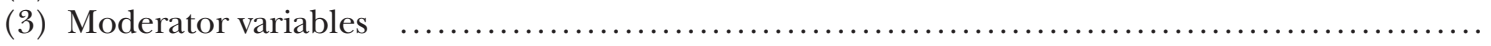

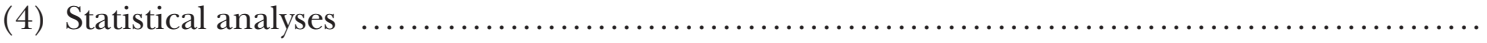

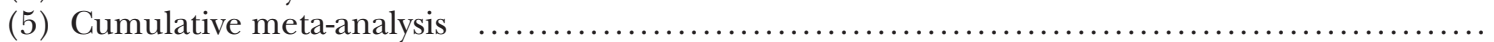

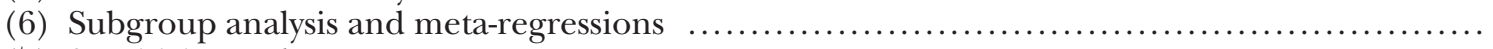

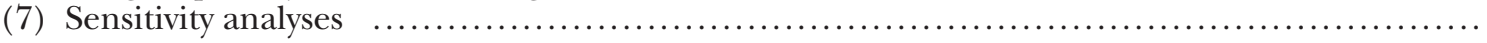

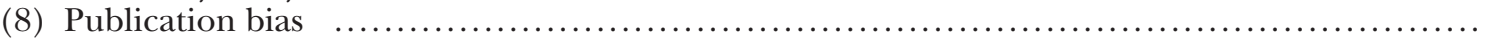

III. Results

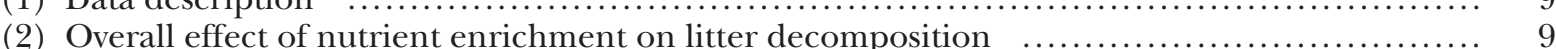

(3) Effects of moderators on the response of litter decomposition to nutrient enrichment $\quad \ldots \ldots \ldots$.

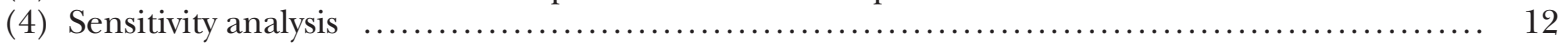

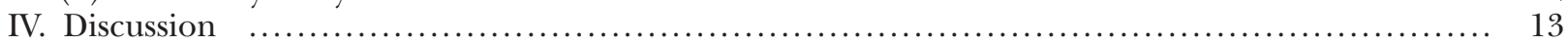

(1) Q1: Does nutrient enrichment affect litter decomposition in running waters? $\ldots \ldots \ldots \ldots \ldots \ldots$

(2) Q2: Do the magnitude and direction of the nutrient-enrichment effect on litter decomposition

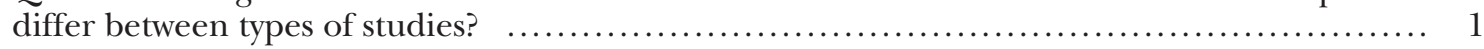

(3) Q3: Are the magnitude and direction of the nutrient-enrichment effects on litter decomposition in manipulative studies influenced by the identity or combination of nutrients added? $\ldots . . . \quad 14$

(4) Q4a: Is there a relationship between the magnitude of the nutrient-enrichment effect on litter decomposition and nutrient availability in reference conditions?

(5) Q4b: Is there a relationship between the magnitude of the nutrient-enrichment effect on litter decomposition and the magnitude of the nutrient enrichment? $\ldots \ldots \ldots \ldots \ldots \ldots \ldots \ldots \ldots \ldots . \ldots 14$

(6) Q5: Do the magnitude and direction of the nutrient-enrichment effects on litter decomposition differ between leaves and wood?

(7) Q6: Are the magnitude and direction of the nutrient-enrichment effects on leaf litter decompo-

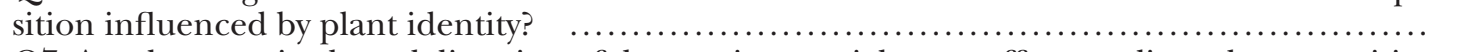

(8) Q7: Are the magnitude and direction of the nutrient-enrichment effects on litter decomposition

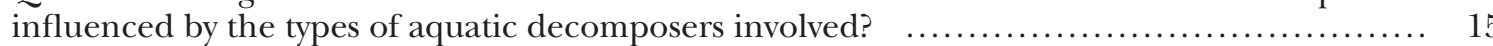

(9) Q8: Do the magnitude and direction of the nutrient-enrichment effects on litter decomposition

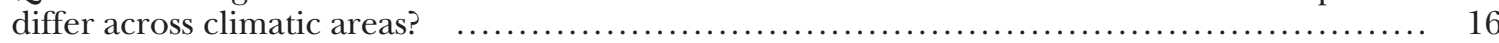

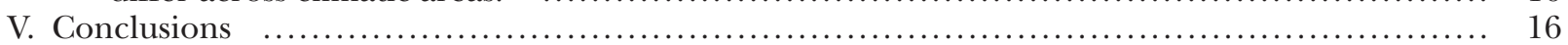

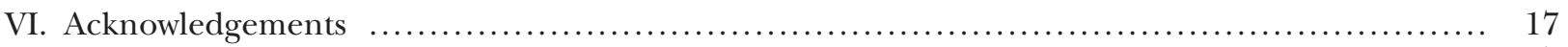

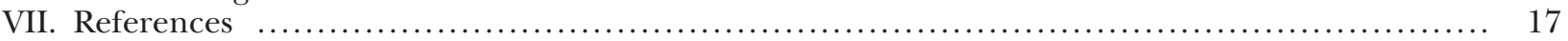

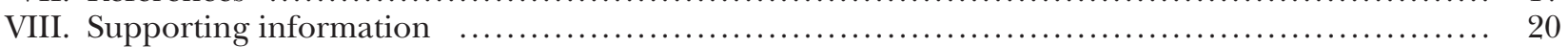

\section{INTRODUCTION}

Over the last decades, human activities have increased nutrient availability in aquatic systems (Vitousek et al., 1997; Rockström et al., 2009), which has resulted in many streams presently being nutrient enriched (Woodward et al., 2012). This trend is likely to continue and intensify in the future due to increases in nutrient loading from agricultural activities, waste water inputs, atmospheric nitrogen $(\mathrm{N})$ deposition (Galloway et al., 2008), invasion of watersheds by N-fixing species (Goldstein, Williard \& Schoonover, 2009), and decreases in stream discharges due to increased water demand and global warming (Murdoch, Baron \& Miller, 2000).
The resulting increase in inorganic nutrient availability in fresh waters has the potential to alter fundamental ecosystem processes such as plant litter decomposition and, consequently, nutrient cycling and energy flow in aquatic ecosystems.

The majority of drainage pathways in most watersheds worldwide are small woodland streams (Allan \& Castillo, 2007). In these streams, the closed riparian vegetation limits instream primary production but supplies large amounts of litter to the streambed. Thus, aquatic food webs obtain most of their energy and carbon from land-derived detritus (Wallace et al., 1997). The decomposition of submerged litter is mainly a biological process, carried out by microbial decomposers and 
invertebrate detritivores (Gessner, Chauvet \& Dobson, 1999; Hieber \& Gessner, 2002). This process is highly sensitive to changes in environmental conditions, such as increases in nutrient availability (Gessner \& Chauvet, 2002; Woodward et al., 2012).

Microbial decomposers have the ability to obtain nutrients from both the organic substrate and the water column (Suberkropp, 1998), but mining N and phosphorus $(\mathrm{P})$ from organic substrates requires the synthesis of multiple extracellular enzymes that are metabolically costly to produce. Therefore, an increase in dissolved inorganic nutrient availability may provide an exogenous nutrient subsidy, which often stimulates microbial activity and litter decomposition (e.g. Niyogi, Simon \& Townsend, 2003; Gulis et al., 2004; Ferreira, Gulis \& Graça, 2006; Gulis, Ferreira \& Graça, 2006). However, some studies have reported no effect of elevated nutrient concentrations on litter mass loss (e.g. Chadwick \& Huryn, 2003; Abelho \& Graça, 2006; Baldy et al., 2007), or even an inhibition of decomposition in highly polluted streams (Pascoal \& Cássio, 2004; Lecerf et al., 2006; Piscart et al., 2009, 2011). These conflicting results suggest that the response of litter decomposition to nutrient enrichment may depend on experimental conditions and/or be confounded by other environmental variables. For instance, because of the simplistic nature and better control of confounding variables (such as temperature, dissolved oxygen concentration, sedimentation, pollutants), stronger responses of litter decomposition to nutrient enrichment are more likely to be found in well-controlled laboratory experiments than in correlative field studies, with intermediate responses in manipulative field studies (Woodward, Perkins \& Brown, 2010).

The simultaneous addition of $\mathrm{N}$ and $\mathrm{P}$ may stimulate litter decomposition to a greater extent than the addition of $\mathrm{N}$ or $\mathrm{P}$ alone since it guarantees that the nutrient limiting the decomposer activity in the system is being added (Grattan \& Suberkropp, 2001). If the background nutrient concentration is already high, further increases in nutrient concentration may, however, not have an effect on litter decomposition since the decomposer demand is already satisfied (Peterson et al., 1993; Grattan \& Suberkropp, 2001). Eventually, in highly eutrophic streams, high ammonium concentrations may become toxic to aquatic invertebrates (Camargo \& Alonso, 2006; Lecerf et al., 2006). Decomposition rates also may be negatively affected by other pollutants (e.g. pesticides) commonly found in such streams (Lecerf et al., 2006; Woodward et al., 2012).

High-quality plant litter (high nutrient, low lignin concentration) usually decomposes faster than low-quality litter (Gessner \& Chauvet, 1994; Ostrofsky, 1997; Lecerf \& Chauvet, 2008b; Schindler \& Gessner, 2009; Ferreira, Encalada \& Graça, 2012). This is particularly evident when leaves (high quality and high surface area to volume ratio) and wood (poor-quality litter due to very low
$\mathrm{N}$ and $\mathrm{P}$ concentrations, high lignin concentration and low surface area to volume ratio) are compared (Gulis et al., 2004; Ferreira et al., 2006; Spänhoff, Augspurger \& Kuesel, 2007a; Arroita et al., 2012). Therefore, an increase in dissolved nutrient availability may have a stronger stimulatory effect on the decomposition of wood, where the microbial community is more nutrient limited, than on leaves (Gulis et al., 2004; Ferreira et al., 2006).

Litter decomposition is often faster when carried out by the complete decomposer community (microbial decomposers and invertebrate detritivores) than by microbial decomposers only (Pascoal et al., 2003; Gulis et al., 2006; Woodward et al., 2012). Invertebrate detritivores rely upon microbial activities that condition plant litter and make it more palatable (Bärlocher \& Kendrick, 1975; Arsuffi \& Suberkropp, 1984; Graça et al., 2001; Chung \& Suberkropp, 2009). Therefore, the direct effects of dissolved nutrients on microbially driven decomposition may be exacerbated by higher invertebrate abundance or activity (Pascoal et al., 2003; Gulis et al., 2006).

The effect of nutrient enrichment on litter decomposition might also depend on water temperature (Ferreira \& Chauvet, 2011), with nutrient enrichment stimulating microbially driven litter decomposition to a greater extent at higher temperatures than in colder waters, where metabolic (e.g. enzymatic) activities may be limited (Chandrashekar \& Kaveriappa, 1991). However, over distinct climatic regions, the effect of water temperature on the response of litter decomposition to nutrient enrichment may be confounded by simultaneous changes in other environmental factors. For example, faster litter decomposition in tropical regions may be hampered by lower detritivore density (Boyero et al., 2011a,b), lower fungal activity (Ferreira et al., 2012), or more recalcitrant litter (Coley \& Barone, 1996) as compared to temperate regions. Therefore, increases in nutrient availability may not necessarily translate into increased litter decomposition rates in the tropics. By contrast, litter decomposition rates in colder climates may be enhanced if biomass of detritivores is high (Irons et al., 1994). Thus, nutrient enrichment in cold regions might stimulate litter decomposition if invertebrate activity exacerbates nutrient effects on microbes.

Conflicting results among studies could also arise if the overall effect of nutrient enrichment on litter decomposition is relatively small and the statistical power (sample size) of individual studies is too low to detect the effect, leading to many non-significant results as well as false negative and positive outcomes. Meta-analyses achieve greater statistical power by combining outcomes of individual studies and weighing them by the inverse of sampling variances. In addition, given the spatial, temporal and statistical limitations found in many individual studies, a comprehensive 
systematic review is necessary to reach a broader understanding of the effects of nutrient enrichment on litter decomposition across a wide range of environments and experimental settings. By combining several independent studies, meta-analyses also allow identification of important drivers of a biological response that could not be tested in individual studies. Although a meta-analytic approach has been used before to address the effects of nutrients on litter decomposition in terrestrial systems (Knorr, Frey \& Curtis, 2005) and on primary production in aquatic systems (Downing, Osenberg \& Sarnelle, 1999; Francoeur, 2001; Elser et al., 2007), there is still no comprehensive quantitative review addressing the effects of nutrient enrichment on litter decomposition in streams (but see Lecerf \& Chauvet, 2008a) despite approximately four decades of studies on the subject.

Here, we present a meta-analysis of 99 studies that addressed the effect of nutrient enrichment on litter decomposition in running waters and were published over the last approximately 40 years. The effects of nutrient enrichment on litter decomposition are likely to be influenced by concomitant changes in other environmental variables (Matthaei, Piggott \& Townsend, 2010; Ferreira \& Chauvet, 2011; Piggott et al., 2012). However, the assessment of the effects of multiple stressors on litter decomposition in streams has begun only recently; thus there are still not enough data to consider multiple stressors or their interactions in the present meta-analysis. Here, we determine the magnitude and direction of the overall effect of nutrient enrichment on litter decomposition and assess what parameters of the incubation conditions influence the magnitude of the effects. Specifically, we test if study type (laboratory versus correlative field studies versus manipulative field studies), identity of the nutrient added in stream manipulative studies ( $\mathrm{N}$ versus $\mathrm{P}$ versus both), nutrient concentration at the reference condition, magnitude of the nutrient enrichment, litter type (leaf versus wood), litter identity (plant genus), type of aquatic community involved in the decomposition process (microbes alone versus microbes and invertebrates), and climate (cold versus temperate versus tropical) modify the effects of nutrient enrichment on litter decomposition. The main questions addressed by our review and hypotheses tested are detailed in Table 1.

\section{METHODS}

\section{(1) Literature survey and selection of relevant primary} studies

We searched for primary studies that addressed the effect of nutrient enrichment on litter decomposition in running waters. These studies were published between January 1970 and July 2012 in English, French, Portuguese and Spanish. The literature search included personal literature databases, electronic journal indices, and electronic reference databases (Google Scholar, Scopus and Web of Science). It targeted not only studies published in international, indexed journals but also those in national journals, theses and reports. No unpublished data were used in the analysis besides the authors' own (V. Gulis, V. Ferreira \& M. A. S. Graça, unpublished data). The search terms used in online databases were '(decomposition OR processing OR breakdown OR decay) AND (litter OR leaf OR leaves OR bark OR wood) AND (nutrient OR nitrate OR nitrogen OR DIN OR phosphorus OR phosphate OR SRP) AND (stream OR river OR water course)', and their equivalents in French, Portuguese and Spanish. The reference lists of relevant primary studies and review papers addressing litter decomposition in fresh waters were also surveyed. Additionally, 143 researchers from 33 countries (49 from North America, 41 from Europe, 30 from Central and South America, 12 from Oceania, 8 from Asia and 3 from Africa) known to work on litter decomposition in streams were contacted and invited to provide references. Fifty percent of researchers replied and contributed seven additional primary studies to the analysis.

Primary studies were included in the analysis if they satisfied the following criteria: $(i)$ they aimed at addressing the effect of experimental nutrient enrichment or human activities (e.g. land use or agriculture) on litter decomposition, (ii) they focused on running waters (i.e. streams, rivers, streamside channels, laboratory microcosms with agitation or forced aeration) rather than standing waters (i.e. lakes, reservoirs, ponds, freshwater marshes or laboratory microcosms without agitation or bubbling), (iii) they compared at least one reference (non-nutrient-enriched) and one nutrient-enriched condition, $(i v)$ they reported decomposition of natural litter (i.e. leaves, bark or wood such as sticks, twigs or veneers) rather than artificial substrates such as cotton strips or cellulose substrates, $(v)$ they relied on litter of allochthonous origin (i.e. riparian trees or grass, and not macrophytes), and (vi) they reported sample size for both reference and nutrient-enriched conditions. The final database included 101 studies that satisfied the above inclusion criteria (see online Appendix S1).

Nutrient enrichment always implies an increase in the concentration of at least one nutrient ( $\mathrm{N}$ or $\mathrm{P})$, even if accompanied by a decrease in the concentration of the other (e.g. Rosemond et al., 2002; Baldy et al., 2007). We considered as a 'case study' any comparison of reference (REF) and nutrient-enriched conditions (NUT). The REF-NUT pairs were either defined in the primary study (e.g. Gulis et al., 2006) or provided after personal communication with the authors (e.g. Woodward et al., 2012). When nutrient gradients were considered, the condition with the lowest nutrient concentration, or described as the least impacted, was treated as the 
Table 1. Questions and hypotheses addressed in this review and the datasets used

\begin{tabular}{|c|c|c|}
\hline Questions & Dataset used & Result \\
\hline $\begin{array}{l}\text { Q1: Does nutrient enrichment } \\
\text { affect litter decomposition in } \\
\text { running waters? }\end{array}$ & $\begin{array}{l}\text { H1: Higher nutrient availability All } \\
\text { stimulates litter } \\
\text { decomposition primarily due } \\
\text { to stimulation of microbial } \\
\text { activities. }\end{array}$ & Fig. 2 \\
\hline
\end{tabular}

Which differences in experimental designs explain variation in the response of litter decomposition to nutrient enrichment among studies?

Q2: Do the magnitude and direction of the nutrient-enrichment effect on litter decomposition differ between types of studies?

Q2a: Do the magnitude and direction of the nutrient-enrichment effect on litter decomposition differ between laboratory and field studies?

Q2b: Do the magnitude and direction of the nutrient-enrichment effect on litter decomposition differ between manipulative and correlative studies?

Q2c: Do the magnitude and direction of the nutrient-enrichment effect on litter decomposition differ between approaches in manipulative studies?

Q3: Are the magnitude and direction of the nutrient-enrichment effect on litter decomposition in manipulative studies influenced by the identity or combination of nutrients added?

Q4a: Is there a relationship between the magnitude of the nutrient-enrichment effect on litter decomposition and nutrient availability in reference conditions?

Q4b: Is there a relationship between the magnitude of the nutrient-enrichment effect on litter decomposition and the magnitude of the nutrient enrichment?
H2a: The effect of nutrient All

Fig. 4A enrichment on litte decomposition is stronger in laboratory than in field studies due to higher simplification and stronger control of potentially confounding variables in the laboratory.

H2b: The effect of nutrient Field studies

Fig. 4A

enrichment on litter

decomposition is stronger in manipulative than in correlative studies due to stronger control of potentially confounding variables in manipulative studies.

H2c: Experimental nutrient enrichment at larger scales (e.g. catchment) has a stronger effect on litter decomposition than nutrient enrichment at smaller scales (e.g. litter bag), since aquatic communities may be more profoundly affected by nutrient addition in the former case.

H3: The simultaneous addition Manipulative studies in streams, leaves of $\mathrm{N}$ and $\mathrm{P}$ stimulates litter decomposition to a larger extent than the addition of each nutrient separately since in the first case it is guaranteed that the limiting nutrient is added.

Manipulative field studies

Fig. 4A

H4a: The effect of nutrient enrichment on litter decomposition is strongest when basal nutrient availability is low and it decreases with increase in the basal nutrient concentration.

H4b: Litter decomposition is positively related to the magnitude of the nutrient enrichment.
Manipulative studies in channels, leaves Laboratory studies

Correlative field studies

Manipulative field studies

Laboratory studies

Correlative field studies

Manipulative field studies
Fig. 4B

Fig. 4B

Fig. S2A, B

Fig. 5A, B

Fig. S3A, B

Fig. S2C, D

Fig. 5C, D

Fig. S3C, 
Table 1. Continued

\begin{tabular}{|c|c|c|c|}
\hline Questions & Hypotheses & Dataset used & Result \\
\hline $\begin{array}{l}\text { Q5: Does the magnitude and direction of } \\
\text { the nutrient-enrichment effect on litter } \\
\text { decomposition differ between leaves } \\
\text { and wood? }\end{array}$ & $\begin{array}{l}\text { H5: The effect of nutrient enrichment } \\
\text { on wood decomposition is stronger } \\
\text { than on decomposition of leaves, } \\
\text { since wood is generally of poorer } \\
\text { nutrient quality, resulting in } \\
\text { associated decomposers being more } \\
\text { nutrient limited. }\end{array}$ & $\begin{array}{l}\text { Manipulative studies } \\
\text { in streams }\end{array}$ & Fig. 6A \\
\hline $\begin{array}{l}\text { Q6: Are the magnitude and direction of } \\
\text { the nutrient-enrichment effect on leaf } \\
\text { litter decomposition influenced by plant } \\
\text { identity? }\end{array}$ & $\begin{array}{l}\text { H6: The effect of nutrient enrichment } \\
\text { on leaf litter decomposition is } \\
\text { stronger for genera with low leaf } \\
\text { nutrient concentration than for } \\
\text { genera with higher leaf nutrient } \\
\text { concentration, since associated } \\
\text { decomposers are more nutrient } \\
\text { limited in the former. }\end{array}$ & $\begin{array}{r}\text { Correlative field } \\
\text { studies, leaves }\end{array}$ & Fig. $6 \mathrm{~B}$ \\
\hline $\begin{array}{l}\text { Q7: Are the magnitude and direction of } \\
\text { the nutrient-enrichment effect on litter } \\
\text { decomposition influenced by the type of } \\
\text { aquatic decomposers involved? }\end{array}$ & $\begin{array}{l}\text { H7: Total litter decomposition (driven } \\
\text { by both microbes and invertebrates) } \\
\text { is stimulated by nutrient enrichment } \\
\text { to a larger extent than microbially } \\
\text { driven litter decomposition, since the } \\
\text { invertebrate activities exacerbate the } \\
\text { stimulatory effect that nutrient } \\
\text { enrichment has on the microbially } \\
\text { driven litter breakdown. }\end{array}$ & $\begin{array}{l}\text { Manipulative studies } \\
\text { in channels, leaves }\end{array}$ & Fig. 7A \\
\hline $\begin{array}{l}\text { Q8: Do the magnitude and direction of } \\
\text { the nutrient-enrichment effect on litter } \\
\text { decomposition differ across climatic } \\
\text { areas? }\end{array}$ & $\begin{array}{l}\text { H8: The effect of nutrient enrichment } \\
\text { on litter decomposition is stronger in } \\
\text { temperate regions, since litter } \\
\text { decomposition is limited by the low } \\
\text { water temperature and the low } \\
\text { abundance of detritivores in cold and } \\
\text { tropical regions, respectively. }\end{array}$ & $\begin{array}{c}\text { Manipulative studies } \\
\text { in streams, leaves }\end{array}$ & Fig. 7B \\
\hline
\end{tabular}

reference to which all the conditions with higher nutrient concentration were compared (e.g. Niyogi et al., 2003). Often, a single study compared the decomposition of several litter species (e.g. Ardón, Stallcup \& Pringle, 2006; Geraldes, 2011) or the effect of different mesh sizes (e.g. Gulis et al., 2006; Woodward et al., 2012) under REF and NUT conditions. Therefore, many individual studies contributed several REF-NUT comparisons to the database making a total of 915 case studies. Although several cases derived from the same study may appear non-independent, their omission from this review would have restrained our analysis of moderators. We thus included them in the analyses because each pair of comparisons actually addressed a different and independent question (e.g. different litter identity or different decomposer community involved). In studies where decomposition values were reported for several dates (Bergfur, 2007; Bergfur et al., 2007a), only those calculated using the last sampling date were considered. The potential effect of inclusion of several cases per study was examined by conducting sensitivity analyses (see Section II.7).

\section{(2) Effect size}

The effect size of nutrient enrichment on the exponential litter decomposition rate per day ( $k$ in day $^{-1}$ ) was calculated as the natural logarithm of the ratio of litter decomposition in the nutrient-enriched condition $\left(k_{\mathrm{NUT}}\right)$ to the litter decomposition in the reference condition $\left(k_{\mathrm{REF}}\right)$, i.e. $\ln \mathrm{R}=\ln \left(k_{\mathrm{NUT}} / k_{\mathrm{REF}}\right)$. LnR are symmetrical around 0 , with positive and negative values indicating an increase or a decrease in the litter decomposition rate associated with nutrient enrichment, respectively. In addition, ln response ratios are normally distributed even in small samples (Hedges, Gurevitch \& Curtis, 1999; Borenstein et al., 2009).

If litter decomposition was reported as exponential decomposition rate per day, which was most often the case, it was used directly in the calculation of the effect size. The $\ln R$ could not be calculated directly from decomposition rate per degree-day $\left(k\right.$ in degree day $\left.{ }^{-1}\right)$, percentage litter mass remaining $(\mathrm{RM} \%)$ or percentage mass litter lost (ML\%) because corresponding REF 
and NUT sometimes differed in mean water temperature and incubation duration. If litter decomposition was reported in these units, it was converted into $k$ in day $^{-1}$, provided that mean water temperature or incubation duration were also given. If not, case studies were excluded from analyses. Case studies where detritus gained mass over the decomposition process (i.e. negative $k$ values in day $^{-1}$ ) were also excluded from the analyses since the increase in mass is an artifact resulting from accumulation of microbial biofilm, primary producers and/or fine sediments that might not have been properly removed during processing of litter samples. These considerations resulted in the removal of 75 case studies from the database, and analyses were performed on the remaining 840 case studies (from 99 studies; see online Table S1).

The variance associated with each $\ln R$ value $\left(\mathrm{V}_{\operatorname{lnR}}\right)$ was calculated from the standard deviation (S.D.) associated with each $k$ in day $^{-1}$ value (Borenstein et al., 2009). If variance associated with mean $k$ in day $^{-1}$ values in the primary studies was reported as standard error (S.E.) or confidence limit (CL), then it was converted into S.D. (Lajeunesse, 2013). In some cases, no measure of variance associated with $k$ in day $^{-1}$ values was given in the primary studies and therefore missing S.D. values were estimated based on the cases in the database that reported S.D. values associated with $k$ in day $^{-1}$ values (Lajeunesse, 2013). However, since any estimation of $k$ in $\mathrm{day}^{-1}$ or S.D. would have a certain degree of inaccuracy, an attempt was made to contact the authors of the primary studies to obtain decomposition results as $k$ in day $^{-1}$ and variation as S.D. to reduce estimations to a minimum. Despite this, estimates of $k$ in day ${ }^{-1}$ and S.D. values had to be made for 44 and $54 \%$ of cases, respectively.

\section{(3) Moderator variables}

Several experimental and environmental factors may affect the magnitude of the response of litter decomposition rate to nutrient enrichment (Table 1). Metaanalysis allows testing the significance and the strength of such factors, referred to as moderators, on effect sizes. Moderators considered in the present meta-analysis corresponded to our hypotheses regarding factors likely to influence the relationship between nutrient enrichment and litter decomposition (Table 1). These included study type (laboratory or field studies), field study type (correlative or manipulative), manipulation scale in field experiments [at the catchment, stream reach (hereafter referred to as 'stream'), streamside channel (hereafter referred to as 'side channel'), or bag scale], identity of the nutrient added in field manipulative experiments (N, P, or both), type of aquatic community involved in litter decomposition (microbes or microbes and invertebrates), litter type (leaves or wood), leaf genus identity, climate (cold, temperate or tropical), mean dissolved inorganic nitrogen (DIN) and soluble reactive phosphorus (SRP) concentrations in REF (continuous variable), and magnitude of the increase in DIN and SRP concentrations in NUT versus REF (continuous variable). It was not possible to assess the interactions between nutrient enrichment and concomitant changes in other environmental factors on litter decomposition due to the limited number of primary studies addressing the effect of multiple stressors. Since agricultural activities not only result in increases in the nutrient load to streams, but also in concomitant changes in other variables (e.g. decrease in dissolved oxygen concentration, increases in the concentration of pesticides, sedimentation), the effects of multiple stressors were implicitly included in correlative studies. For descriptions of moderator variables and levels see Table S2. Information on moderators was extracted from primary studies when available (see online Table S1), otherwise, the authors were contacted.

\section{(4) Statistical analyses}

All statistical analyses were performed in RStudio (RStudio, 2012) with the metafor package (Viechtbauer, 2010). A random-effects model of meta-analysis was used to determine the grand mean, i.e. the overall effect of nutrient enrichment on litter decomposition. Random-effects models account for extra variation in effect sizes not encapsulated by within-study variance (i.e. $\left.\mathrm{V}_{\operatorname{lnR}}\right)$. In this analysis, individual effect sizes $(\ln R)$ were weighted by the reciprocal of their corresponding variance $\left(1 / \mathrm{V}_{\operatorname{lnR}}\right)$ to account for differences in accuracy among studies. The mean effect size was considered as significantly different from 0 if its $95 \%$ CL did not include 0 (Borenstein et al., 2009).

\section{(5) Cumulative meta-analysis}

Cumulative meta-analysis was performed on all case studies to assess whether the mean effect size of nutrient enrichment on litter decomposition changed significantly over the time period considered in this meta-analysis. Since it is difficult to assign chronological order to studies published within the same year, we first calculated the mean effect size per study and then averaged mean effects of studies for each year. Cumulative meta-analysis then was performed on these yearly mean effects by adding them in ascending chronological order using a random-effects model. The cumulative ln-mean effect size for each year was considered as significantly different from 0 if its $95 \%$ CL did not include 0 (Leimu \& Koricheva, 2004; Borenstein et al., 2009). To facilitate interpretation, the ln-mean effect size was back-transformed into mean effect size, which illustrates the magnitude of difference in $k$ in day $^{-1}$ between NUT and REF. For mean effect size, significant effects existed when the 95\% CL did not include 1 . 


\section{(6) Subgroup analysis and meta-regressions}

The effects of moderators on the magnitude and direction of the litter decomposition response to nutrient enrichment were assessed for subsets of the database according to our questions and available sample size; only moderator levels with at least three case studies were compared (Table 1; Fig. 1; see online Table S1). The test of moderators in meta-analysis is similar to weighted ANOVA in which each value of the response variable $(\operatorname{lnR})$ is weighted by the reciprocal of its variance $\left(1 / \mathrm{V}_{\mathrm{lnR}}\right)$. We used mixed-effects models to compare heterogeneity between $\left(Q_{B}\right)$ and within $\left(Q_{W}\right)$ moderator levels to assess the significance of each categorical moderator (Borenstein et al., 2009). Two groups (levels) were significantly different if their 95\% CL did not overlap (Borenstein et al., 2009). To facilitate interpretation of the results, the ln-mean effect size was back-transformed into mean effect size and significant effects existed when the $95 \%$ CL did not include 1 .

To avoid potential confounding factors, the moderators were tested hierarchically (Table 1, Fig. 1). The overall difference in effect size between the laboratory and the field case studies was tested first using the whole dataset. Further analyses were restricted to case studies from the field experiments only. We first tested for the difference between manipulative and correlative field studies. Because of significant differences between the two factor levels, we pursued our hierarchical approach analysing other moderators for manipulative and correlative field studies separately. Figure 1 and Table 1 summarize the order and corresponding datasets used in the analyses.
Weighted regressions were used to assess the relationship between effect sizes ( $\ln R)$ and continuous variables: mean DIN and SRP concentrations in REF, and magnitude of the increase in DIN and SRP concentrations between REF and NUT (all ln-transformed). Meta-regressions were performed for laboratory, correlative field and manipulative field experiments using the mixed-effects models.

\section{(7) Sensitivity analyses}

Studies by Bärlocher \& Corkum (2003) and Woodward et al. (2012) made a large contribution to the overall dataset, with $44 \%$ of cases for laboratory experiments (66 cases) and $16 \%$ of cases for field studies (108 cases), respectively. Because such a large contribution might have biased our results, we carried out a sensitivity analysis by removing these case studies and repeating the analyses. In addition, to assess possible bias in effect sizes due to the inclusion of case studies that did not go through the peer-review process (i.e. grey literature), all analyses were repeated on a data subset excluding such cases. Also, to assess for possible bias in effect sizes due to the inclusion of case studies for which $k$ in day $^{-1}$ and/or S.D. had to be estimated, the analyses were repeated on a data subset excluding such studies. Finally, to account for the possible non-independence of case studies taken from the same primary paper, analyses were repeated using mean effect size per study, which was calculated as the weighted mean effect size of all cases considered within that study using a mixed-effects model.

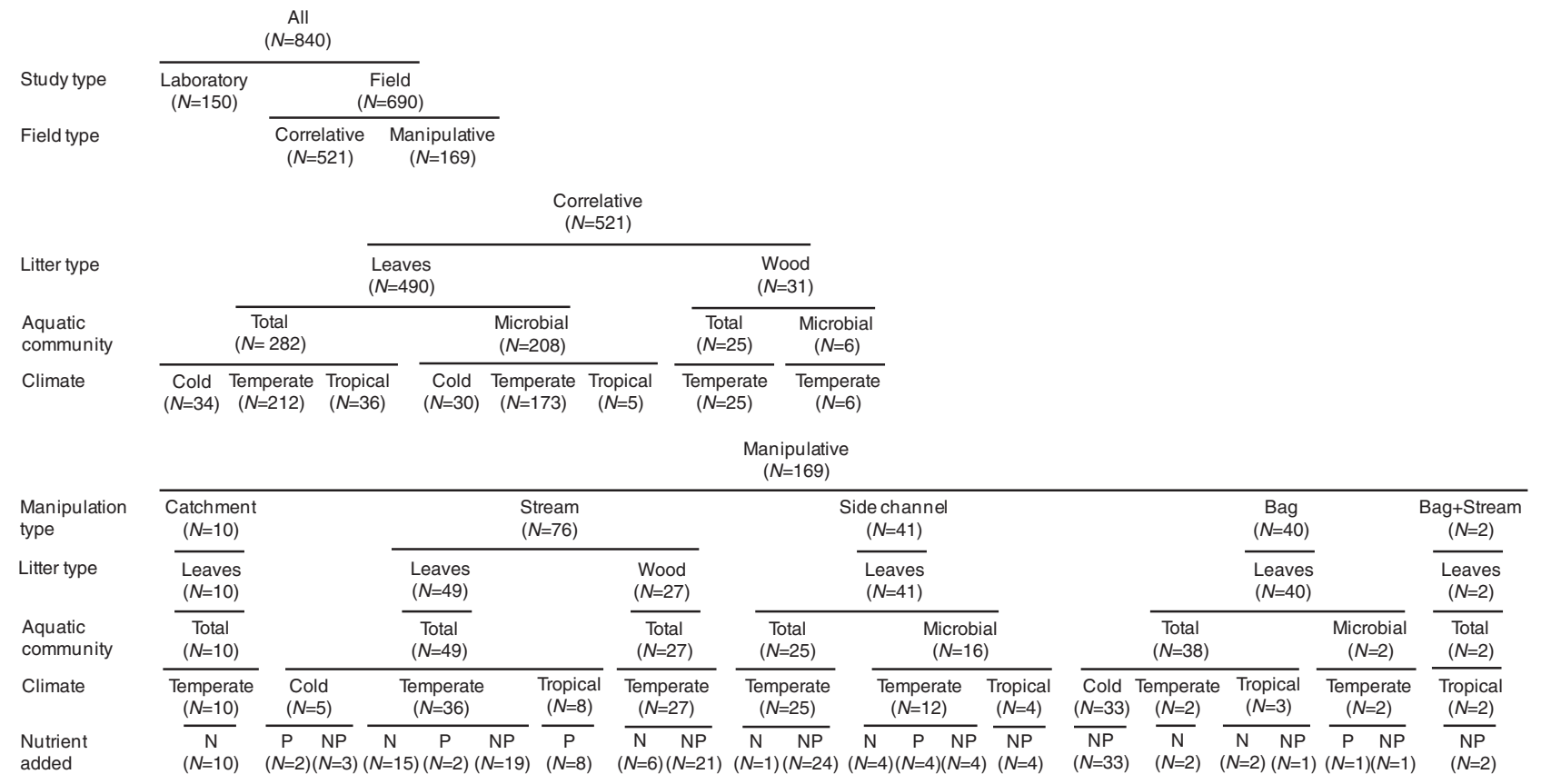

Fig. 1. Design of the database showing the number of cases per moderator variable. See Table S2 for descriptions of moderator variables. 


\section{(8) Publication bias}

Evidence of publication bias in the overall database and datasets used in the analyses was assessed by the funnel plot and by the Rosenthal's fail-safe number (Borenstein et al., 2009). For the overall database, the funnel plot, which is a scatter plot of effect sizes against sample sizes from individual studies, was symmetrical, which suggests the absence of publication bias. The Rosenthal's fail-safe number gives the number of missing case studies with non-significant results that would be necessary to nullify the combined effect size. It would 1625080 . Even if we assume that each missing study contribute 108 case studies (the largest number of case studies contributed by a study in the present database), this converts into 15047 missing studies, 30 times higher than the threshold for considering the results robust $(5 N+10$, where $N=$ number of studies in the database).

\section{RESULTS}

\section{(1) Data description}

Out of 99 primary studies included in this review, $44 \%$ were conducted in Europe, 36\% in North America, 9\% in Oceania, $9 \%$ in Central and South America, and 1\% in Asia (see online Appendix S1, Fig. S1). The earliest studies included in this review were from 1976 (Howarth \& Fisher, 1976; Triska \& Sedell, 1976), but $77 \%$ of the studies were published between 2000 and summer 2012 (see online Appendix S1, Table S1).

Correlative studies in which litter decomposition was assessed along landscape gradients of dissolved nutrients were the most common type of study $(62 \%)$, followed by manipulative field experiments (20\%), and laboratory studies (18\%) (Fig. 1; see online Table S1). Among field studies, the decomposition of leaf litter was the most studied (92\% of cases), while decomposition of wood was addressed to a lesser extent $(8 \%)$. The effect of nutrient enrichment on total litter decomposition (i.e. driven by microbes and invertebrates) was studied most often (66\% of cases), while the effect on microbially driven decomposition was addressed in $34 \%$ of cases (Fig. 1; see online Table S1). Most cases for field studies came from temperate regions $(77 \%)$, while only $15 \%$ came from cold regions (boreal and alpine) and $8 \%$ from tropical areas. Most field manipulative studies addressed the combined effect of $\mathrm{N}$ and $\mathrm{P}$ enrichment on litter decomposition ( $66 \%$ of cases), while the effect of $\mathrm{N}$ or $\mathrm{P}$ alone was addressed in 24 and $10 \%$ of cases, respectively (Fig. 1; see online Table $\mathrm{S} 1$ ).

\section{(2) Overall effect of nutrient enrichment on litter decomposition}

The grand mean effect size was 1.49 (95\% CL: 1.41-1.58), corresponding to a significant increase

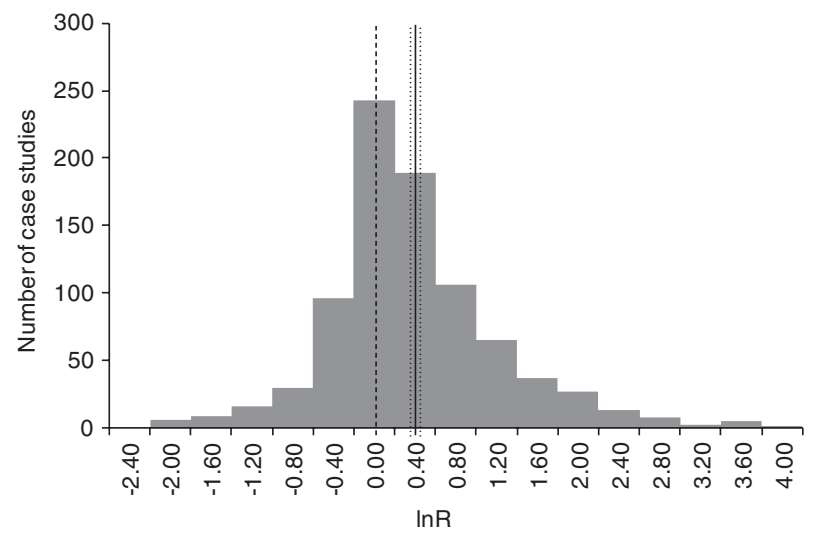

Fig. 2. Frequency distribution of effect sizes for 840 case studies. The mean effect size is indicated by the solid line and the associated $95 \%$ CL by the dotted lines. The dashed line $(\ln R=0)$ indicates no effect of nutrient enrichment on litter decomposition. Positive effect sizes indicate stimulation of litter decomposition by nutrient enrichment, and negative effect sizes indicate a decrease in litter decomposition associated with nutrient enrichment.

(approximately 50\%) in litter decomposition rate with nutrient enrichment (Table 1, Q1; Fig. 2; see online Table S3). The combined effect size of nutrient effect on litter decomposition did not differ significantly from 1 between 1976 and 1994 (Fig. 3). From 1995 onwards, the combined effect size suggested a significant stimulation of litter decomposition with nutrient enrichment. Evidence accumulated over the last 17 years has increased the precision of the estimate but did not change its magnitude; by 2012, the combined effect size was positive and significantly different from 1 (Fig. 3).

\section{(3) Effects of moderators on the response of litter decomposition to nutrient enrichment}

Several experimental and environmental characteristics of the primary studies affected the response of litter decomposition to nutrient enrichment. Specifically, the effect of the type of study was significant $\left(Q_{\mathrm{B}}=113.33, \quad\right.$ d.f. $\left.=1, \quad P<0.0001\right)$, with stronger responses to enrichment found in laboratory than in field studies (Table 1, Q2a; Fig. 4A; see online Table S3). The type of field study also affected the response of litter decomposition to nutrient enrichment $\left(Q_{\mathrm{B}}=13.35\right.$, d.f. $\left.=1, P<0.001\right)$, with stronger effects in manipulative than in correlative studies (Table 1, Q2b; Fig. 4A; see online Table S3). Within manipulative studies, the scale of manipulation affected the response of decomposition to enrichment $\left(Q_{B}=63.08\right.$, d.f. $=3, P<0.0001$ ) (Table 1, Q2c; Fig. 4A; see online Table S3). Manipulative studies at the stream scale revealed a significant stimulation of litter decomposition with nutrient enrichment. In side channels, the stimulation was marginally significant, while no significant effect was observed in studies manipulating 


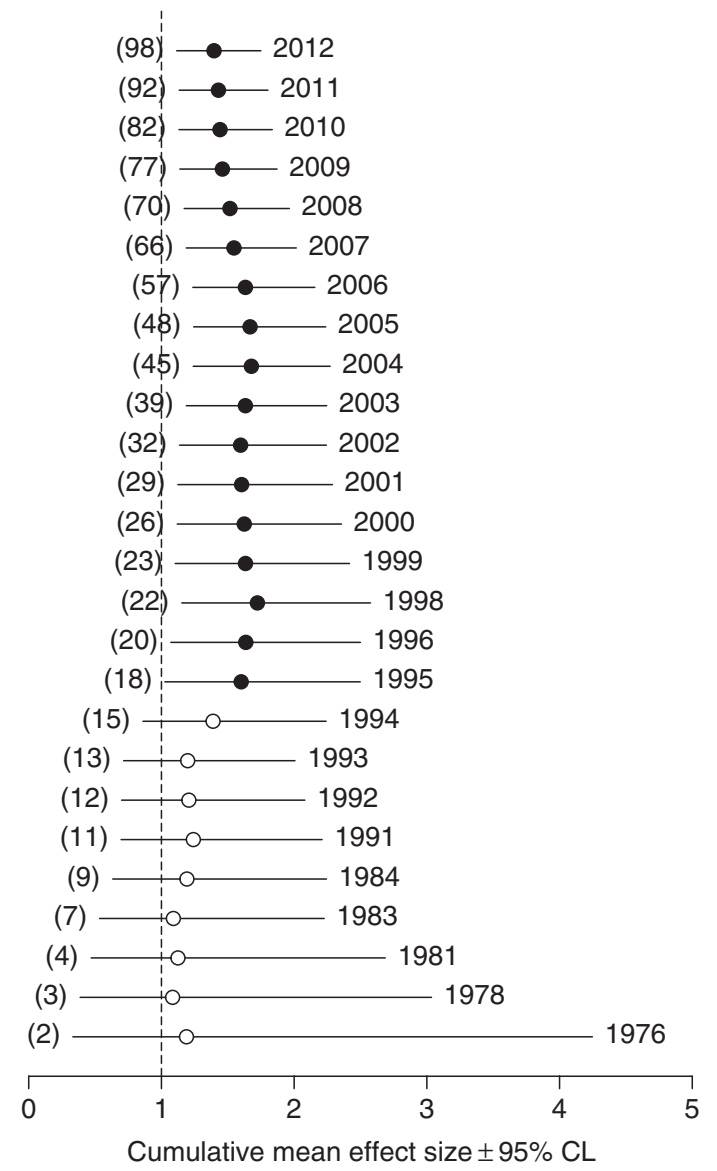

Fig. 3. Trends in cumulative meta-analysis results over time. For each year, the mean effect size was calculated by performing a meta-analysis of all previous years based on the mean effect size of each primary study. The dashed line (mean effect size $=1$ ) indicates no effect of nutrient enrichment on litter decomposition. The mean effect size is significant when the $95 \%$ CL does not overlap 1 (black circles). The number of primary studies accumulated by each year is given in parentheses; the total number of primary studies accumulated by 2012 is 98 because the unpublished study (V. Gulis, V. Ferreira \& M. A. S. Graça, unpublished data) was not included in this analysis.

nutrient concentration at the catchment or at the litter bag scales (Fig. 4A; see online Table S3).

In manipulative studies, the identity and combination of nutrients added (N, P, or both) affected the response of leaf decomposition to nutrient enrichment, but it depended on the scale of manipulation [significant 'manipulation scale $\times$ nutrient added' interaction: log-likelihood ratio test $(\mathrm{LLR})=11.13, \quad P=0.004]$ (Table 1, Q3; Fig. 4B; see online Table S3). In manipulative studies in streams and side channels, the addition of both nutrients stimulated leaf decomposition whereas the addition of $\mathrm{P}$ did not result in significant effects (Fig. 4B; see online Table S3). The addition of $\mathrm{N}$ alone stimulated litter decomposition in streams, but not in side channels (Fig. 4B; see online Table S3).
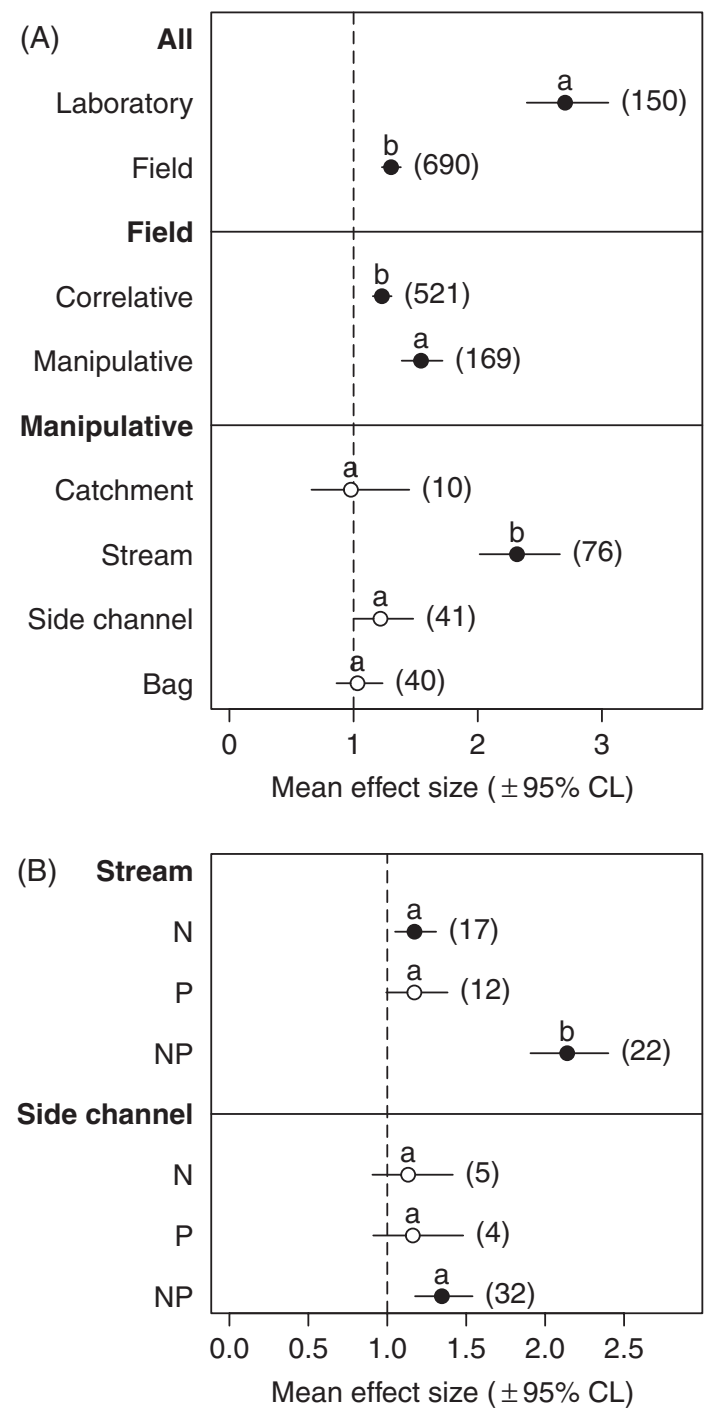

Fig. 4. (A) Effect of nutrient enrichment on litter decomposition in different types of studies, and (B) effects of enrichment with $\mathrm{N}, \mathrm{P}$ or their combination on leaf litter decomposition in manipulative studies in streams and side channels. The dashed line (mean effect size $=1$ ) indicates no effect of nutrient enrichment on litter decomposition, mean effect size $>1$ indicates stimulation, and mean effect size $<1$ indicates inhibition. The effect of nutrient enrichment is significant when the $95 \%$ CL does not overlap 1 (black circles). Within each dataset (indicated in bold, see Table 1 for details), levels with the same letter do not differ significantly in their response to nutrient enrichment. Values in parentheses indicate sample size.

For laboratory cases, effect sizes were negatively related to the mean DIN concentration in REF treatments, but not to SRP (Table 1, Q4a; see online Fig. S2A, B, Table S4). In correlative field studies, effect sizes were negatively related to the mean DIN and SRP concentrations in REF (Table 1, Q4a; Fig. 5A, B; see online Table S4). In manipulative field studies, no significant relationship was found between nutrient 

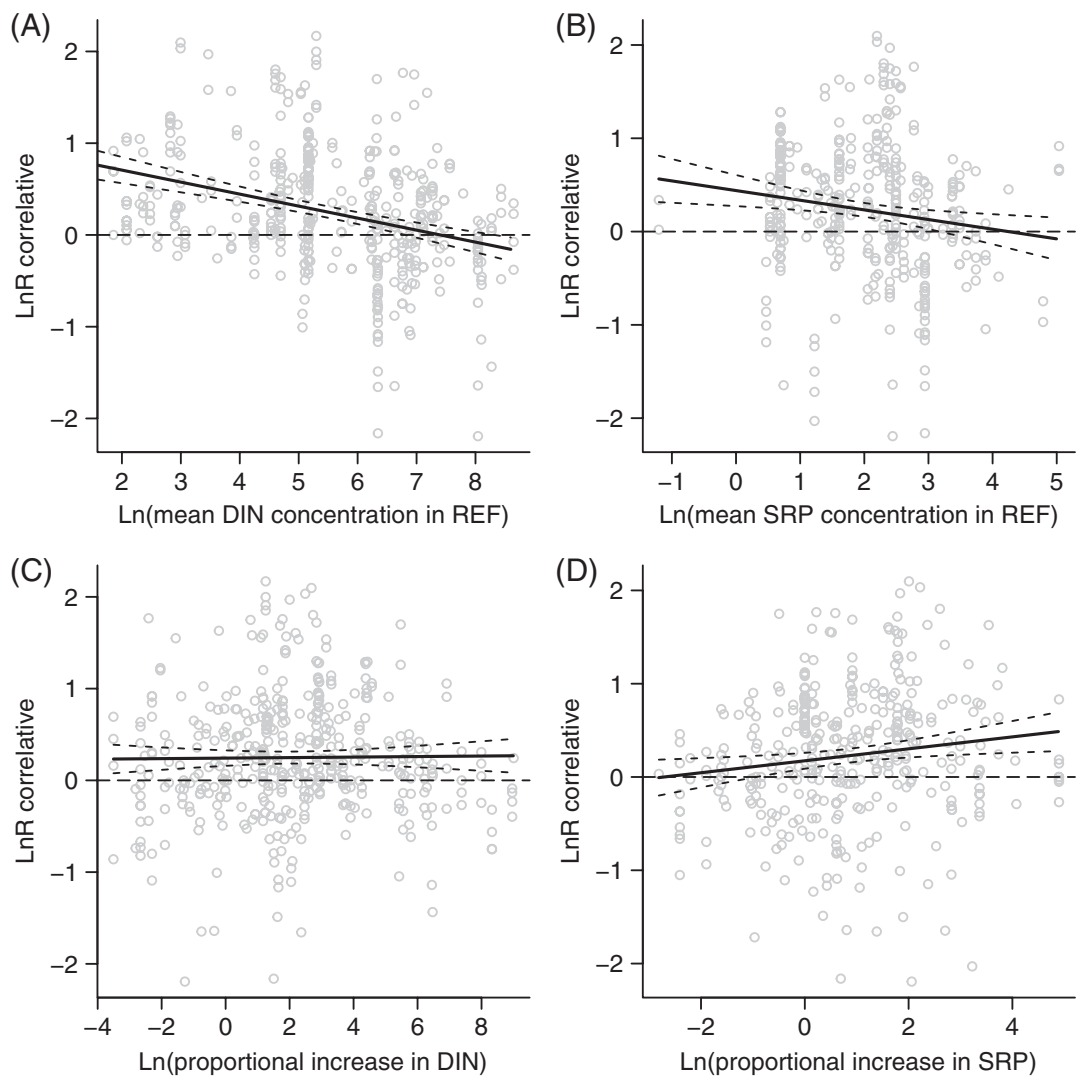

Fig. 5. Effects of mean dissolved inorganic nitrogen (DIN; A) and soluble reactive phosphorus (SRP; B) concentrations in reference conditions (REF), and magnitude of the increase in DIN (C) and SRP (D) concentrations in nutrient-enriched conditions (NUT) versus REF, on litter decomposition $(\operatorname{lnR})$, for correlative field studies. The dashed line $(\ln R=0)$ indicates no effect of nutrient enrichment on litter decomposition, $\ln R>0$ indicates stimulation, and $\ln R<0$ indicates inhibition. The relationship (meta-regression) is shown by the solid line and the associated $95 \%$ CL by the dashed lines.

concentration in REF and effect sizes (Table 1, Q4a; see online Table S4, Fig. S3A, B).

When laboratory cases were considered, effect sizes were positively related to the magnitude of increase in DIN and SRP concentrations in NUT relative to REF (Table 1, Q4b; see online Fig. S2C, D, Table S4). For correlative studies, effect sizes were positively related to the magnitude of increase in SRP concentration in NUT relative to REF, while the magnitude of increase in DIN had no effect (Table 1, Q4b; Fig. 5C, D; see online Table S4). By contrast, for manipulative studies, a positive relationship was found between the effect size and the magnitude of increase in DIN concentration, but not in SRP concentration (Table 1, Q4b; see online Table S4, Fig. S3C, D).

The type of litter affected the response of litter decomposition to nutrient enrichment, but the effect varied between correlative and manipulative studies (significant 'study type $\times$ litter type' interaction: $L L R=51.62$, $P<0.0001$ ) (Table 1, Q5; Fig. 6A; see online Table S3), which were therefore analysed separately. In correlative studies, the response of litter decomposition to nutrient enrichment was not affected by the litter type $\left(Q_{B}=0.38\right.$, d.f. $\left.=1, P=0.540\right)$, although nutrient enrichment significantly stimulated the decomposition of leaves, but not that of wood (Fig. 6A; see online Table S3). In manipulative stream studies, however, the type of litter affected the magnitude of the response of litter decomposition to nutrient enrichment $\left(Q_{\mathrm{B}}=91.60\right.$, d.f. $=1, P<0.0001)$, with much stronger effects for wood than for leaves (Fig. 6A; see online Table S3).

The identity of the leaf litter affected the response of leaf decomposition to nutrient enrichment in correlative studies $\left(\mathrm{Q}_{\mathrm{B}}=140.60\right.$, d.f. $\left.=14, P<0.0001\right)$ (Table 1 , Q6; Fig. 6B; see online Table S3). The decomposition of Liriodendron, Acer, Ficus, and Quercus leaves was significantly stimulated by nutrient enrichment, while the decomposition of Fagus and Trema leaves was significantly inhibited in NUT conditions (Fig. 6B; see online Table S3).

The type of aquatic community involved in leaf decomposition did not affect the response of leaf decomposition to nutrient enrichment neither in correlative studies $\left(\mathrm{Q}_{\mathrm{B}}=0.37\right.$, d.f. $\left.=1, P=0.545\right)$ nor in manipulated side channels $\left(Q_{\mathrm{B}}=3.21\right.$, d.f. $=1, P=$ 0.073 ) (no 'study type $\times$ community type' interaction: 
LLR $=0.41, P=0.523$ ) (Table 1, Q7; Fig. 7A; see online Table S3). In correlative studies, both microbially driven and total decomposition were stimulated by nutrient enrichment, while in manipulative studies, the effect of nutrients was only significant for microbially driven decomposition (Fig. 7A; see online Table S3).

The climate type did not affect the response of leaf decomposition to nutrient enrichment either in correlative studies $\left(Q_{\mathrm{B}}=4.13\right.$, d.f. $\left.=2, P=0.127\right)$ or in manipulative stream studies $\left(Q_{B}=2.27\right.$, d.f. $=2$, $P=0.322$ ) (no 'study type $\times$ climate' interaction: $L L R=$ 1.78, $P=0.410$ ) (Table 1, Q8; Fig. 7B; see online Table S3). In general, nutrient enrichment stimulated leaf decomposition in all field studies in all climates, with the only exception being manipulative stream experiments in the tropics (Fig. 7B; see online Table S3).

\section{(4) Sensitivity analysis}

Sensitivity analyses showed that when primary studies that contributed a disproportionally high number of cases (Bärlocher \& Corkum, 2003; Woodward et al., 2012), unpublished studies or case studies for which $k$ in day $^{-1}$ and/or S.D. values had to be estimated were removed from the database, the trends and interpretations were not qualitatively changed, except for the effect of mean nutrient concentration in REF, magnitude of the nutrient enrichment between NUT and REF, and climate (see online Tables S4-S7). The removal of Bärlocher \& Corkum (2003) and Woodward et al. (2012) cases from the database resulted in the appearance of a significant positive relationship between the magnitude of the DIN enrichment and effect sizes in correlative studies (see online Table S4). The removal of unpublished cases or estimated cases from the database resulted in the disappearance of the negative relationship between mean SRP concentration in REF and effect sizes in correlative studies (see online Table S4). The removal of estimated cases from the database resulted in the disappearance of $(i)$ the negative relationship between mean DIN concentration in REF and effect sizes in laboratory studies, (ii) the positive relationships between the magnitude of the nutrient enrichment and effect sizes in laboratory studies, and (iii) the negative relationship between mean SRP concentration in REF and effect sizes in correlative studies, and in the appearance of $(i)$ a negative relationship between mean DIN concentration and effect sizes in manipulative studies and (ii) a positive relationship between the magnitude of SRP enrichment and effect sizes in manipulative studies (see online Table S4). When either Bärlocher \& Corkum (2003) and Woodward et al. (2012) or unpublished studies were removed from the database, the degree to which leaf decomposition in correlative studies was stimulated by nutrient enrichment became dependent on climate, with a stronger response in cold than in temperate climates $\left(Q_{B}=5.75\right.$, d.f. $=2, P=0.056$, and $Q_{\mathrm{B}}=6.34$, d.f. $=2, P=0.042$,
(A)

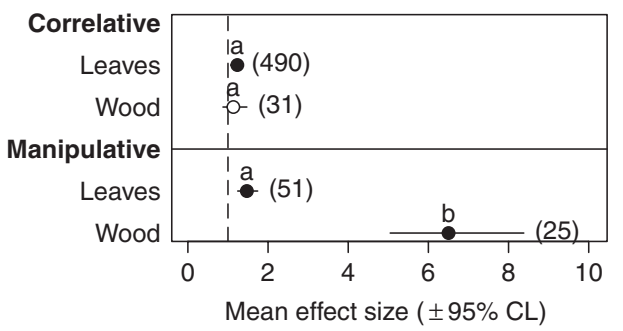

(B)

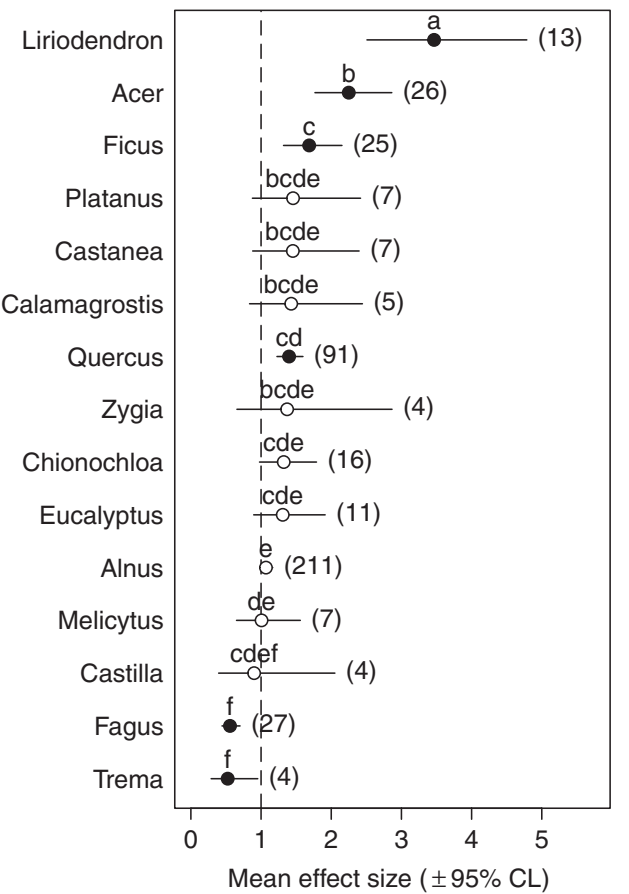

Fig. 6. Effect of nutrient enrichment on decomposition rates (A) of leaves and wood in correlative and manipulative studies in streams, and (B) of leaves from different genera in correlative field studies. The dashed line (mean effect size $=1$ ) indicates no effect of nutrient enrichment on litter decomposition, mean effect size $>1$ indicates stimulation, and mean effect size $<1$ indicates inhibition. The effect of nutrient enrichment is significant when the $95 \%$ CL does not overlap 1 (black circles). Within each dataset (indicated in bold, see Table 1 for details), levels with the same letter do not differ significantly in their response to nutrient enrichment. Values in parentheses indicate sample size.

respectively; see online Tables S5 and S6). When estimated cases were removed from the database, the response of litter decomposition to nutrient enrichment in correlative studies in tropical streams disappeared, and the effect size was stronger in cold than in temperate or tropical regions $\left(Q_{B}=10.32\right.$, d.f. $=2$, $P=0.006$; see online Table S7). When only an averaged mean effect size per study was considered, results did not change qualitatively regarding the response of litter decomposition to nutrient enrichment, although they did not depend on study type or manipulation scale (see online Table S8). 
(A)

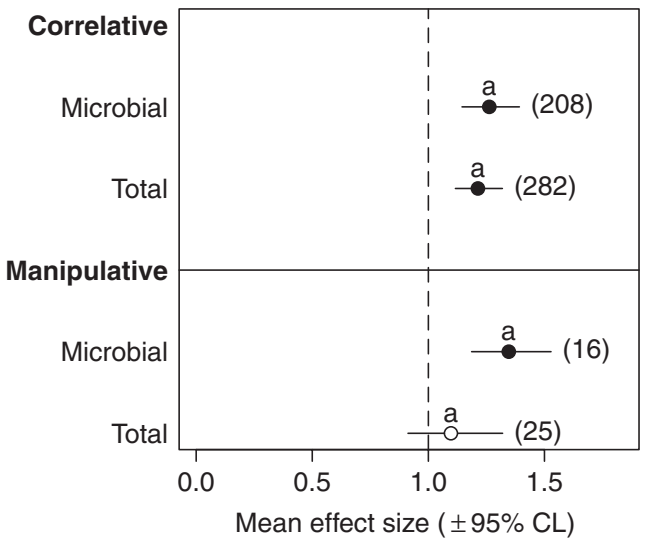

(B)

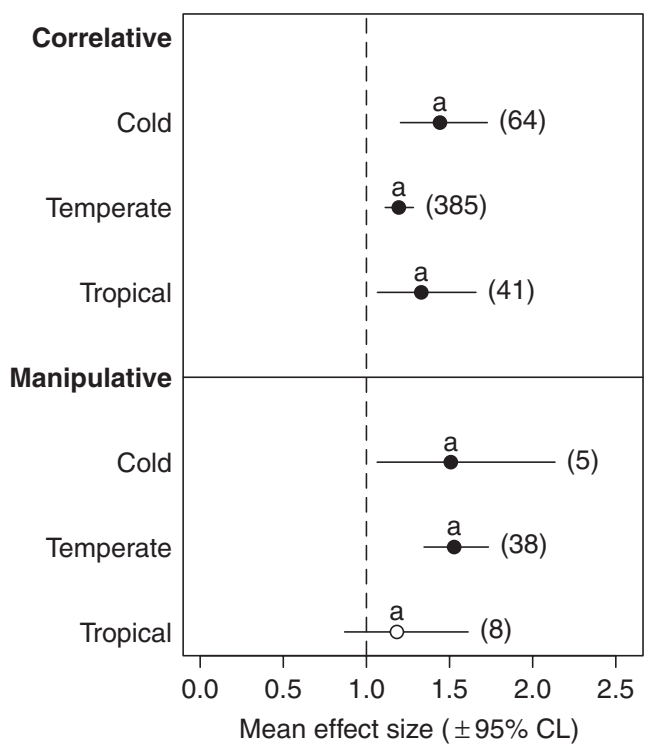

Fig. 7. Effect of nutrient enrichment (A) on microbially driven and total (microbial and invertebrate) leaf litter decomposition in correlative field studies and in manipulative studies in stream side channels, and (B) on leaf litter decomposition in cold, temperate and tropical climates in correlative and manipulative studies in streams. The dashed line (mean effect size $=1$ ) indicates no effect of nutrient enrichment on leaf decomposition, mean effect size $>1$ indicates stimulation, and mean effect size $<1$ indicates inhibition. The effect of nutrient enrichment is significant when the $95 \%$ CL does not overlap 1 (black circles). Within each dataset (indicated in bold, see Table 1 for details), levels with the same letter do not differ significantly in their response to nutrient enrichment. Values in parentheses indicate sample size.

\section{DISCUSSION}

In this first meta-analysis of the effects of nutrient enrichment on litter decomposition in streams, we have shown that overall decomposition is significantly stimulated by nutrient addition and revealed a number of environmental and experimental variables that modify the magnitude of the response.

\section{(1) Q1: Does nutrient enrichment affect litter} decomposition in running waters?

This meta-analysis of approximately 40 years of studies addressing the effect of nutrient enrichment on litter decomposition in running waters showed stimulation of litter decomposition by approximately $50 \%$. However, cumulative meta-analysis revealed that an overall significant response of litter decomposition to nutrient enrichment was found only from 1995 onward. The rapid growth in the number of studies addressing this issue in recent years has contributed to the increased precision of effect estimates, but did not change the magnitude or direction of the effect size over the last two decades.

\section{(2) Q2: Do the magnitude and direction of the nutrient-enrichment effect on litter decomposition differ between types of studies?}

The type of study affected the response of litter decomposition to nutrient enrichment. The magnitude of the effect size was in the order: laboratory studies $>$ manipulative field studies $>$ correlative field studies. As hypothesized, the observed differences can be explained by an increase in complexity of the system under assessment and a concomitant decrease in the ability to control potentially confounding variables from laboratory towards correlative field studies. In the majority of cases, correlative field studies were carried out in agricultural landscapes where intensification of agricultural practices results in increased nutrient loads, but also leads to increases in fine sediment load (Niyogi et al., 2003; Hagen, Webster \& Benfield, 2006). Fine sediments have been shown to lower benthic invertebrate densities and diversity (Matthaei et al., 2010; Piggott et al., 2012). Since Plecoptera and Trichoptera (which constitute a major portion of detritivore taxa) are among the most sensitive invertebrates (Carlisle et al., 2007), an increase in fine sediments can result in decreases in litter decomposition rates (Young, Matthaei \& Townsend, 2008). In some cases, however, fine sediments might stimulate litter decomposition due to physical abrasion or smothering of submerged detritus (Matthaei et al., 2010; Piggott et al., 2012). Agricultural practices, including increases in fine sediment load, can also lead to decreases in dissolved oxygen availability (Pascoal \& Cássio, 2004; Hagen et al., 2006), which have been shown negatively to affect fungal decomposers (Medeiros, Pascoal \& Graça, 2009). Additionally, agricultural practices are frequently associated with the use of pesticides, which negatively affects aquatic biota (microbial and invertebrate decomposers) and litter decomposition (Schäfer et al., 2007; Rasmussen et al., 2012). Finally, high concentrations of ammonium can become toxic to aquatic macroinvertebrates (Camargo, Alonso \& Salamanca, 2005; Camargo \& Alonso, 2006; Lecerf et al., 2006) resulting in decreased decomposition rates (Pascoal \& Cássio, 
2004; Lecerf et al., 2006; Woodward et al., 2012). Correlative field studies are therefore likely to underestimate the intrinsic effect of nutrient enrichment on litter decomposition. Nevertheless, correlative studies allow assessment of the effect of nutrient enrichment in combination with concomitant changes in other environmental factors under realistic field conditions (e.g. agricultural activity, waste water discharge), although they do not allow discrimination between the effects of nutrient enrichment per se and other accompanying variables.

The significant response of litter decomposition to nutrient enrichment in manipulative studies was driven by the large effect size observed in studies that manipulated nutrient concentrations at the stream scale. Indeed, litter decomposition was more responsive to experimental nutrient enrichment at larger scales: stream > side channel > litter bag. Litter decomposers are uniformly and continuously exposed to nutrient enrichment when enrichment operates at the whole-stream scale (Elwood et al., 1981; Rosemond et al., 2002; Gulis \& Suberkropp, 2003c; Benstead et al., 2005; Ferreira et al., 2006). However, the continuous experimental addition of nutrients at the stream scale may not perfectly simulate streams that suffer from intermittent nutrient inputs (e.g. waste water plant discharges, run-off events). To our knowledge, only one primary study attempted to assess how nutrient addition frequency affects litter decomposition in streams, but reported no effects of nutrient enrichment, either continuous or intermittent (Triska \& Sedell, 1976). Nutrient enrichment at the litter bag scale, on the other hand, was often attempted by using diffusing substrates (e.g. fertilizer pellets or agarized media), which do not provide uniform controllable nutrient release at either temporal or spatial scales (Abelho \& Graça, 2006; McKie et al., 2009; Abelho et al., 2010). Therefore, we suggest that this approach to address the effect of nutrient enrichment on litter decomposition should be abandoned. The effect of experimental nutrient enrichment at the catchment scale, the largest scale considered, was not significant, probably due to small sample size (a single study with 10 cases; Chadwick \& Huryn, 2003). Also, while Chadwick \& Huryn (2003) simulated atmospheric $\mathrm{N}$ deposition, the N-enriched stream might have experienced $\mathrm{P}$ limitation.

The strong response of litter decomposition to nutrient enrichment in laboratory studies is likely to be a result of highly controlled conditions (i.e. isolation and manipulation of the factors and organisms of interest) and well-replicated designs, which are usually not possible under field conditions. These characteristics of laboratory studies make them very useful for clarifying the mechanisms by which environmental factors affect litter decomposition. However, the simplistic nature of these studies, due to the impossibility of reproducing within a microcosm all the possible biotic and abiotic interactions that characterize real ecosystems, seriously limits the ability to scale up the results.

(3) Q3: Are the magnitude and direction of the nutrient-enrichment effects on litter decomposition in manipulative studies influenced by the identity or combination of nutrients added?

Manipulative studies differed in the type of nutrient added (N, P or both), with the simultaneous addition of both nutrients having stronger effects on litter decomposition than the addition of either $\mathrm{N}$ or $\mathrm{P}$ alone, suggesting possible nutrient co-limitation. Similarly, stronger effects of the combination of nutrients have been found for primary producers (e.g. Francoeur, 2001; Elser et al., 2007). Also, the similar effect sizes found when either $\mathrm{N}$ or $\mathrm{P}$ were added alone suggest that stream decomposers are almost equally likely to be limited by either nutrient, as already suggested for benthic algae (Francoeur, 2001).

(4) Q4a: Is there a relationship between the magnitude of the nutrient-enrichment effect on litter decomposition and nutrient availability in reference conditions?

Nutrient concentration in reference conditions was also an important factor determining the response of litter decomposition to nutrient enrichment in laboratory and correlative studies. At low N (both study types) and $\mathrm{P}$ concentrations (correlative studies), nutrient enrichment stimulated litter decomposition, but the effect of enrichment was not significant when the background nutrient concentration was already high. This suggests that when microbial decomposers are not nutrient-limited, further increases in nutrient availability will not stimulate litter decomposition (Grattan \& Suberkropp, 2001). A similar pattern was found for the effect of $\mathrm{P}$ addition on phytoplankton growth in marine environments (Downing et al., 1999). Thus, the interpretation of the effects of nutrient enrichment on litter decomposition must take into consideration the background nutrient concentrations.

(5) Q4b: Is there a relationship between the magnitude of the nutrient-enrichment effect on litter decomposition and the magnitude of the nutrient enrichment?

The relationship between the response of litter decomposition and the magnitude of $\mathrm{N}$ enrichment differed between study types, with stronger positive relationships for laboratory studies, followed by manipulative studies; no relationship was observed for correlative studies. In correlative studies, small and large increases in $\mathrm{N}$ had comparable effects on litter decomposition, which suggests that at high $\mathrm{N}$ concentrations either 
ammonium became toxic to invertebrates (Camargo \& Alonso, 2006; Lecerf et al., 2006) or that these high $\mathrm{N}$ concentrations were accompanied by changes in other variables that counteracted the stimulating effect of $\mathrm{N}$ on microbes (Woodward et al., 2012) (see Q2 above). A similar pattern has been found for the effect of $\mathrm{N}$ addition on litter decomposition in terrestrial systems (Knorr et al., 2005). However, when the study by Woodward et al. (2012) was excluded from the analysis, the relationship between effect sizes and the magnitude of $\mathrm{N}$ enrichment in correlative studies became positive as cases with the largest increases in $\mathrm{N}$ concentration were removed. These cases were also potentially those with the largest changes in other variables that could have counteracted the stimulatory effect of nutrient increase, such as decrease in dissolved oxygen concentration or increase in pesticide concentrations. Also, it has been shown that microbial nutrient demands can be satisfied at relatively low levels of nutrient availability with the relationship between microbial activities and dissolved nutrient concentration following a Michaelis-Menten saturation-type model; the concentration at which half of the maximum rate of activity is achieved was estimated at $16-303 \mu \mathrm{gl}^{-1}$ for nitrate-N and $7-21 \mu \mathrm{gl}^{-1}$ for SRP (Rosemond et al., 2002; Ferreira et al., 2006; Gulis et al., 2006). Thus, increases in dissolved nutrient concentration beyond the half-saturation point will not translate into proportional increases in decomposition rates.

(6) Q5: Do the magnitude and direction of the nutrient-enrichment effects on litter decomposition differ between leaves and wood?

We anticipated a stronger effect of nutrient enrichment on the decomposition of wood than of leaf litter since wood has lower initial $\mathrm{N}$ and $\mathrm{P}$ concentrations and, therefore, associated microbial decomposers may respond to external nutrients to a greater extent (Stelzer, Heffernan \& Likens, 2003; Gulis et al., 2004; Ferreira et al., 2006; Spänhoff et al., 2007b; Young \& Collier, 2009). Indeed, nutrient enrichment stimulated wood decomposition to a greater extent than that of leaf litter in stream manipulative studies. However, this can be explained in part by the common use of wood veneers in whole-stream enrichment experiments. Wood veneers have relatively high surface area to volume ratio as compared to sticks or branches (cylindrical shape) and as a result display higher microbial activity per unit mass. The higher microbial activity on veneers makes the decomposition of this substrate more sensitive to the effects of nutrients than that of sticks or branches. In correlative studies, nutrient enrichment did not significantly affect wood decomposition and only slightly stimulated leaf decomposition due to a multitude of confounding factors in such studies, including pollution (see Q2 above).
(7) Q6: Are the magnitude and direction of the nutrient-enrichment effects on leaf litter decomposition influenced by plant identity?

Plant species differ in leaf physical and chemical characteristics (Ostrofsky, 1997), and it is plausible that the leaf decomposition of nutrient-poor plant species is more responsive to nutrient enrichment than that of nutrient-rich species (Gulis \& Suberkropp, 2003c; Ferreira et al., 2006; Gulis et al., 2006), although other leaf traits (lignin concentration, toughness, wax or cuticle, etc.) may also modify the effects of litter nutrient concentration on decomposition (Lecerf \& Chauvet, 2008b). Alnus and Quercus leaves were most frequently used in correlative studies, and, therefore, their effect sizes are the most robust. Conversely, the sample sizes for many plant genera were small and therefore the effect sizes should be interpreted with caution. Effect sizes were higher for genera with low (e.g. Quercus) and intermediate $\mathrm{N}$ concentration (e.g. Acer, Ficus), and non-significant for high-N litter (e.g. Alnus) (Ostrofsky, 1997). Contrary to expectations, however, the decomposition of the nutrient-poor Fagus leaf litter (Gessner \& Chauvet, 1994) was generally lower under nutrient enrichment. This can be explained by the fact that most Fagus cases came from two studies where the gradient in nutrient concentration was negatively related to a decrease in the density of a key detritivore species (Gammarus pulex) (Piscart et al., 2009, 2011). Also, the decomposition of poor-quality Eucalyptus leaf litter was not significantly affected by nutrient enrichment, which might be partially attributed to its high concentration of essential oils and polyphenolics and thick cuticle, which usually delays colonization by micro-organisms and detritivores (Canhoto \& Graça, 1999) and might render this litter less sensitive to nutrient enrichment (Abelho et al., 2010; Geraldes, 2011; but see Mesquita, Pascoal \& Cássio, 2007; Molinero, Pozo \& González, 1996). Since there are differences in effect sizes among plant genera, any conclusion regarding the effect of nutrient enrichment on litter decomposition should be interpreted in light of the identity/quality of the litter used.

(8) Q7: Are the magnitude and direction of the nutrient-enrichment effects on litter decomposition influenced by the types of aquatic decomposers involved?

In litter decomposition studies, it is common to incubate litter protected from or exposed to macroinvertebrates to estimate the relative contributions of microbial and invertebrate decomposers to litter processing. Since microbial activity is generally stimulated by nutrient enrichment (Suberkropp \& Chauvet, 1995; Niyogi et al., 2003; Gulis \& Suberkropp, 2003c; Gulis et al., 2004; Ferreira et al., 2006; Gulis, Suberkropp \& Rosemond, 2008), and the activity of detritivores on submerged 
litter is usually stimulated by microbial conditioning (Bärlocher \& Kendrick, 1975; Arsuffi \& Suberkropp, 1984; Graça et al., 2001; Chung \& Suberkropp, 2009), we anticipated a stronger effect of nutrient enrichment on total than on microbially driven litter decomposition (Pascoal et al., 2003; Gulis et al., 2006). Contrary to predictions, however, the type of community involved in leaf decomposition did not affect the response of decomposition to nutrient enrichment, which suggests that nutrients did not significantly modify the interactions between microbial and metazoan decomposers or their net outcomes. Also, detritivores may not always be important players in litter decomposition, especially in streams where nutrient (e.g. ammonium) enrichment attains toxic levels to invertebrates or is accompanied by increases in sedimentation or other pollutants as in many streams affected by agriculture (Niyogi et al., 2003; Lecerf et al., 2006; Piscart et al., 2009, 2011). However, nutrient enrichment significantly stimulated microbially driven leaf decomposition in correlative field studies and manipulative experiments in streamside channels. This contrasts with the results from a previous meta-analysis (Lecerf \& Chauvet, 2008a), which reported no significant response of microbially driven leaf decomposition to nutrient enrichment in human-altered streams. These varying results can be attributed to differences in sample size: in our case, the effect of nutrient enrichment on microbial-driven leaf decomposition in correlative studies was based on 208 NUT-REF comparisons, while in the meta-analysis of Lecerf \& Chauvet $(2008 a)$ the effect size was based on six stream pairs.

(9) Q8: Do the magnitude and direction of the nutrient-enrichment effects on litter decomposition differ across climatic areas?

Climate can potentially influence the effect of nutrient enrichment on litter decomposition. Our results, however, did not reveal any significant effect of climate on the response of leaf decomposition to nutrient enrichment, despite the significant effect of nutrient enrichment on leaf decomposition in cold and temperate regions and the non-significant effect size in manipulative stream studies in the tropics. When case studies from Bärlocher \& Corkum (2003) and Woodward et al. (2012), unpublished studies, and those in which $k$ day $^{-1}$ and/or S.D. values had to be estimated were excluded from analyses, the effect size became significantly higher in cold than in temperate (and tropical) regions, which suggests that the effect of nutrient enrichment on litter decomposition across climatic regions may be affected by biogeographic patterns of invertebrate abundance and diversity (Boyero et al., 2011b). These results are, however, limited by the lower sample sizes in cold and tropical regions.

\section{CONGLUSIONS}

(1) This meta-analysis has shown that increases in dissolved nutrient availability stimulate litter decomposition, potentially altering the energy flow and nutrient cycling in streams. This stimulation is stronger when the background nutrient concentrations are low and the magnitude of the nutrient enrichment is high.

(2) The response of litter decomposition to nutrient enrichment depends, however, on the type of study, with much stronger effects in the laboratory than in the field. This suggests that, although laboratory studies are useful in elucidating the mechanisms by which target variables affect litter decomposition, the magnitude of the nutrient enrichment effect on litter decomposition observed in the laboratory may overestimate the effects occurring in the field. The effects of nutrient enrichment on ecosystem-level processes should be addressed under realistic field conditions.

(3) The response of litter decomposition to nutrient enrichment is also stronger for field manipulative studies than for correlative studies; the latter suffering from various confounding effects, including pollutants that inhibit biological processing of detritus in streams affected by human activity. Experimental nutrient manipulations at the stream scale allow the effect of a single variable (nutrient) on litter decomposition to be addressed specifically, while assessing the response of litter decomposition to nutrient enrichment (eutrophication) due to human activities (e.g. agriculture) includes the effects of concomitant changes in other environmental factors. Both approaches can contribute to our understanding of the effects of nutrient enrichment on litter decomposition in a variety of scenarios.

(4) For field manipulative studies, the response of litter decomposition to nutrient enrichment depends on the type of manipulation, with much stronger effects when nutrient enrichment is done at the stream than at the litter-bag scale. In the latter case, it is usually difficult to provide uniform controllable nutrient releases at either temporal or spatial scale, and therefore we suggest that this approach should be abandoned.

(5) The response of litter decomposition to nutrient enrichment is the strongest for low-quality leaf litter (high C:N ratio) and wood, as on these substrates fungal decomposers experience more severe nutrient limitation than on nutrient-rich substrates. Therefore, the identity and type of the litter used should be taken into consideration when evaluating the effect of nutrient enrichment in streams. Since litter decomposition has been proposed as an indicator of stream functional integrity (Gessner \& Chauvet, 2002; Young et al., 2008), low-quality litter will likely be more effective in detecting an impairment than high-quality litter (Gulis et al., 2006)

(6) While the overall effects of nutrient enrichment on decomposition of leaf litter in streams are generally 
understood, our knowledge on decomposition of submerged woody substrates and plant litter other than tree leaves that may play an important role in stream ecosystem functioning (e.g. Ward \& Aumen, 1986) is lagging.

(7) Our meta-analysis uncovered a suite of general patterns describing the response of plant decomposition to nutrient enrichment at a global scale. Nevertheless, further studies are needed to address questions that presently have small sample sizes. For example, most studies reviewed here came from Europe and the USA; studies from Central and South America came mostly from a single region in Costa Rica, whereas studies from Asia, Africa and tropical areas are under-represented.

(8) Several potentially important moderator variables of the nutrient effect on litter decomposition need to be addressed in future studies, such as nutrient addition frequency (continuous versus intermittent) and the interaction between nutrient enrichment and changes in other environmental factors likely to occur concomitantly (e.g. warming, decreases in dissolved oxygen availability, sedimentation, increases in pesticide concentrations, changes in litter quality). The effects of multiple stressors and their interactions on stream ecosystem functioning started to be addressed only recently, and some studies suggest that the effect of nutrients on litter decomposition can be significantly altered by changes in other environmental variables (Matthaei et al., 2010; Ferreira \& Chauvet, 2011; Piggott et al., 2012).

\section{ACKNOWLEDGEMENTS}

We thank the collaboration of many authors who provided information that was not included in the primary studies, and the patience of those who undertook the task of digging through old datasets to find the requested data. Financial support by the Portuguese Foundation for Science and Technology (FCT) to V.F. (postdoctoral fellowship SFRH/BPD/76482/2011, program POPH/FSE) and NSF DEB 0919054 to V.G. is gratefully acknowledged. This review benefited from comments provided by the anonymous reviewers.

\section{REFERENCES}

*References marked with asterisk have been cited within the supporting information.

Abelho, M. \& Graça, M. A. S. (2006). Effects of nutrient enrichment on decomposition and fungal colonization of sweet chestnut leaves in an Iberian stream (Central Portugal). Hydrobiologia 560, 239-247.

Abelho, M., Morreti, M., Franca, J. \& Callisto, M. (2010). Nutrient addition does not enhance leaf decomposition in a Southeastern Brazilian stream (Espinhaço mountain range). Brazilian Journal of Biology 70, 747-754.

Allan, J. D. \& Castillo, M. M. (2007). Stream Ecology. Structure and Function of Running Waters. Springer, Dordrecht.

Ardón, M., Stallcup, L. A. \& Pringle, C. M. (2006). Does leaf quality mediate the stimulation of leaf breakdown by phosphorus in Neotropical streams? Freshwater Biology 51, 618-633.

Arroita, M., Aristi, I., Flores, L., Larrañaga, A., Díez, J., Mora, J., Romaní, A. M. \& Elosegi, A. (2012). The use of wooden sticks to assess stream ecosystem functioning: comparison with leaf breakdown rates. Science of the Total Environment 440, 115-122.

Arsuffi, T. L. \& Suberkropp, K. (1984). Leaf processing capabilities of aquatic hyphomycetes: interspecific differences and influence on shredder feeding preferences. Oikos 42, 144-154

*Au, D. W. T., Hodgkiss, I. J. \& Vrijmoed, L. L. P. (1992). Decomposition of Bauhinia purpurea leaf litter in a polluted and unpolluted Hong Kong waterway. Canadian Journal of Botany 70, 1061-1070.

Baldy, V., Gobert, V., Guerold, F., Chauvet, E., Lambrigot, D. \& CharcosSET, J.-Y. (2007). Leaf litter breakdown budgets in streams of various trophic status: effects of dissolved inorganic nutrients on microorganisms and invertebrates. Freshwater Biology 52, 1322-1335.

BÄrLOCHER, F. \& CORKum, M. (2003). Nutrient enrichment overwhelms diversity effects in leaf decomposition by stream fungi. Oikos 101, 247-252.

Bärlocher, F. \& KeNdrick, B. (1975). Leaf-conditioning by microorganisms. Oecologia 20, 359-362.

Benstead, J. P., Deegan, L. A., Peterson, B. J., Huryn, A. D., Bowden, W. B., Suberkropp, K., Buzby, K. M., Green, A. C. \& VAcca, J. A. (2005). Responses of a beaded Arctic stream to short-term N and P fertilisation. Freshwater Biology 50, 277-290.

BERGFur, J. (2007). Seasonal variation in leaf-litter breakdown in nine boreal streams: implications for assessing functional integrity. Fundamental and Applied Limnology/Archiv für Hydrobiologie 169, 319-329.

Bergfur, J., Johnson, R. K., Sandin, L. \& Goedkoop, W. (2007a). Assessing the ecological integrity of boreal streams: a comparison of functional and structural responses. Fundamental and Applied Limnology/Archiv für Hydrobiologie 169, 113-125.

*Bergfur, J., Johnson, R. K., Sandin, L., Goedkoop, W. \& Nygren, K. (2007b). Effects of nutrient enrichment on boreal streams: invertebrates, fungi and leaf-litter breakdown. Freshwater Biology 52, 1618-1633.

BIRD, G. A. \& KAUSHIK, N. K. (1992). Invertebrate colonization and processing of maple leaf litter in a forested and an agricultural reach of a stream. Hydrobiologia 234, 65-77.

Borenstein, M., Hedges, L. V., Higgins, J. P. T. \& Rothstein, H. R. (2009). Introduction to Meta-Analysis. John Wiley \& Sons, Ltd, Chichester.

Boyero, L., Pearson, R. G., Dudgeon, D., Graca, M. A. S., Gessner, M. O., Albarino, R. J., Ferreira, V., Yule, C. M., Boulton, A. J., Arunachalam, M., Callisto, M., Chauvet, E., Ramirez, A., Chara, J., Moretti, M. S., Goncalves, F. Jr., Helson, J. E., Chará-Serna, A. M., Encalada, A. C., Davies, J. N., Lamothe, S., Cornejo, A., Li, A. O. Y., Buria, L. M., Villanueva, V. D., Zuniga, M. C. \& Pringle, C. M. (2011a). Global distribution of a key trophic guild contrasts with common latitudinal diversity patterns. Ecology 92, 1839-1848.

Boyero, L., Pearson, R. G., Gessner, M. O., Barmuta, L. A., Ferreira, V., Graça, M. A. S., Dudgeon, D., Boulton, A. J., Callisto, M., Chauvet, E., Helson, J. E., Bruder, A., Albariño, R. J., Yule, C. M., Arunachalam, M., Davies, J. N., Figueroa, R., Flecker, A. S., Ramírez, A., Death, R. G., Iwata, T., Mathooko, J. M., Mathuriau, C., Goncalves, J. F. Jr., Moretti, M. S. Jingut, T., Lamothe, S., M'Erimba, C., Ratnarajah, L., Schindler, M. H., Castela, J., Buria, L. M., Cornejo, A., Villanueva, V. D. \& West, D. C. $(2011 b)$. A global experiment suggests climate warming will not accelerate litter decomposition in streams but may reduce carbon sequestration. Ecology Letters 14, 289-294.

Camargo, J. A. \& Alonso, A. (2006). Ecological and toxicological effects of inorganic nitrogen pollution in aquatic ecosystems: a global assessment. Environmental International 32, 831-849.

Camargo, J. A., Alonso, A. \& Salamanca, A. (2005). Nitrate toxicity to aquatic animals: a review with new data for freshwater invertebrates. Chemosphere $\mathbf{5 8}$, $1255-1267$.

Canhoto, C. \& Graça, M. A. S. (1999). Leaf barriers to fungal colonization and shredders (Tipula lateralis) consumption of decomposing Eucalyptus globulus. Microbial Ecology 37, 163-172.

Carlisle, D. M., Meador, M. R., Moulton, S. R. II \& Ruhl, P. M. (2007). Estimation and application of indicator values for common macroinvertebrate genera and families of the United States. Ecological Indicators 7, 22-33.

*Castela, J., Ferreira, V. \& Graça, M. A. S. (2008). Evaluation of stream ecological integrity using litter decomposition and benthic invertebrates. Environmental Pollution 153, 440-449.

Chadwick, M. A. \& Huryn, A. D. (2003). Effect of a whole-catchment $\mathrm{N}$ addition on stream detritus processing. Journal of the North American Benthological Society 22, 194-206.

Chandrashekar, K. R. \& Kaveriappa, K. M. (1991). Production of extracellular cellulase by Lunulospora curvula and Flagellospora penicillioides. Folia Microbiologica 36, 249-255.

*Cheever, B. M., Kratzer, E. B. \& Webster, J. R. (2012). Immobilization and mineralization of $\mathrm{N}$ and $\mathrm{P}$ by heterotrophic microbes during leaf decomposition. Freshwater Sciences 31, 133-147. 
Chung, N. \& Suberkropp, K. (2009). Contribution of fungal biomass to the growth of the shredder, Pycnopsyche gentilis (Trichoptera: Limnephilidae). Freshwater Biology 54, 2212-2224.

Coley, P. D. \& Barone, J. A. (1996). Herbivory and plant defenses in tropical forests. Annual Review of Ecology and Systematics 27, 305-335.

*Dang, C. K., Chauvet, E. \& Gessner, M. O. (2005). Magnitude and variability of process rates in fungal diversity-litter decomposition relationships. Ecology Letters 8, 1129-1137.

*Del Arco, A. I. O., Ferreira, V. \& Graça, M. A. S. (2012). The performance of biological indicators in assessing the ecological state of streams with varying catchment urbanisation levels in Coimbra, Portugal. Limnetica 31 , $141-154$.

*Dítez, J., Elosegi, A., Chauvet, E. \& Pozo, J. (2002). Breakdown of wood in the Agüera stream. Freshwater Biology 47, 2205-2215.

Downing, J. A., OsenberG, C. W. \& SArnelle, O. (1999). Meta-analysis of marine nutrient-enrichment experiments: variation in the magnitude of nutrient limitation. Ecology 80, 1157-1167.

*Duarte, S., Pascoal, C. \& Cássio, F. (2008). High diversity of fungi mitigate the impact of pollution on plant litter decomposition in streams. Microbial Ecology 56, 688-695.

*Duarte, S., Pascoal, C., Garabetian, F., Cássio, F. \& Charcosset, J.-Y. (2009). Microbial decomposer communities are mainly structured by trophic status in circumneutral and alkaline steams. Applied and Environmental Microbiology 75, 6211-6221.

Elser, J. J., Bracken, M. E. S., Cleland, E. E., Gruner, D. S., Harpole, W. S., Hillebrand, H., Ngai, J. T., Seabloom, E. W., Shurin, J. B. \& Smith, J. E. (2007). Global analysis of nitrogen and phosphorus limitation of primary producers in freshwater, marine and terrestrial ecosystems. Ecology Letters 10, $1135-1142$.

Elwood, J. W., Newbold, J. D., Trimble, A. F. \& Stark, R. W. (1981). The limiting role of phosphorus in a woodland stream ecosystem: effects of $\mathrm{P}$ enrichment on leaf decomposition and primary production. Ecology 62, $146-158$.

*Fairchild, J. F., Boyle, T. P., Robinson-Wilson, E. \& Jones, J. R. (1984). Effects of inorganic nutrients on microbial leaf decomposition and mitigation of chemical perturbation. Journal of Freshwater Ecology 2, 405-416.

*Fernandes, E.L. (2011). Eutrophication alters the effects of riparian plant diversity on litter decomposition by macroinvertebrates. Masters Thesis: University of Minho.

*Fernandes, I., Duarte, S., Cássio, F. \& Pascoal, C. (2009). Mixtures of zinc and phosphate affect leaf litter decomposition by aquatic fungi in streams. Science of the Total Environment 407, 4283-4288.

Ferreira, V. \& Chauvet, E. (2011). Synergistic effects of water temperature and dissolved nutrients on litter decomposition and associated fungi. Global Change Biology 17, 551-564.

Ferreira, V., Encalada, A. C. \& Graça, M. A. S. (2012). Effects of litter diversity on decomposition and biological colonization of submerged litter in temperate and tropical streams. Freshwater Sciences 31, 945-962.

*Ferreira, V. \& Graca, M. A. S. (2007). Fungal activity associated with decomposing wood is affected by nitrogen concentration in water. International Review of Hydrobiology 92, 1-8.

Ferreira, V., Gulis, V. \& GracA, M. A. S. (2006). Whole-stream nitrate addition affects litter decomposition and associated fungi but not invertebrates. Oecologia 149, 718-729.

Francoeur, S. N. (2001). Meta-analysis of lotic nutrient amendment experiments: detecting and quantifying subtle responses. Journal North American Benthological Society 20, 358-368.

Galloway, J. N., Townsend, A. R., Erisman, J. W., Bekunda, M., Cai, Z., Freney, J. R., Martinelli, L. A., Seitzinger, S. P. \& Sutton, M. A. (2008). Transformation of the nitrogen cycle: recent trends, questions, and potential solutions. Science 320, 889-892.

Geraldes, P. (2011). Fungal communities and functional measures as indicators of stream ecosystem health. Masters Thesis: University of Minho.

Gessner, M. O. \& Chauvet, E. (1994). Importance of stream microfungi in controlling breakdown rates of leaf litter. Ecology 75, 1807-1817.

Gessner, M. O. \& Chauvet, E. (2002). A case for using litter breakdown to assess functional stream integrity. Ecological Applications 12, 498-510.

Gessner, M. O., Chauvet, E. \& Dobson, M. (1999). A perspective on leaf litter breakdown in streams. Oikos 85, 377-384.

Goldstein, C. L., Williard, K. W. J. \& Schoonover, J. E. (2009). Impact of an invasive exotic species on stream nitrogen levels in southern Illinois. Journal of the American Water Resources Association 45, 664-672.

Graça, M. A. S., Cressa, C., Gessner, M. O., Feio, M. J., Callies, K. A. \& BARrios, C. (2001). Food quality, feeding preferences, survival and growth of shredders from temperate and tropical streams. Freshwater Biology 46, 947-957.

Grattan, R. M. II \& Suberkropp, K. (2001). Effects of nutrient enrichment on Yellow Poplar leaf decomposition and fungal activity in streams. Journal North American Benthological Society 20, 33-43.
GREENwOOD, J. (2004). The response of autotrophic and heterotrophic resources to a long-term nutrient enrichment in an Appalachian headwater stream. PhD Thesis: University of Georgia.

* Greenwood, J. L., Rosemond, A. D., Wallace, J. B., Cross, W. F. \& Weyers, H. S. (2007). Nutrients stimulate leaf breakdown rates and detritivore biomass: bottom-up effects via heterotrophic pathways. Oecologia 151, 637-649.

Griffith, M. B. \& Perry, S. A. (1994). Fungal biomass and leaf litter processing in streams of different water chemistry. Hydrobiologia 294, 51-61.

*Griffiths, N. A., Tank, J. L., Royer, T. V., Rosi-Marshall, E. J., Whiles, M. R., Chambers, C. P., Frauendorf, T. C. \& Evans-White, M. A. (2009). Rapid decomposition of maize detritus in agricultural headwater streams. Ecological Applications 19, 133-142.

Gulis, V., Ferreira, V. \& Graça, M. A. S. (2006). Stimulation of leaf litter decomposition and associated fungi and invertebrates by moderate eutrophication: implications for stream assessment. Freshwater Biology 51, 1655-1669.

Gulis, V., Rosemond, A. D., Suberkropp, K., Weyers, H. S. \& Benstead, J. (2004). Effects of nutrient enrichment on the decomposition of wood and associated microbial activity in streams. Freshwater Biology 49, 1437-1447.

*Gulis, V. \& Suberkropp, K. (2003a). Effects of inorganic nutrients on relative contributions of fungi and bacteria to carbon flow from submerged decomposing leaf litter. Microbial Ecology 45, 11-19.

*Gulis, V. \& Suberkropp, K. (2003b). Interactions between stream fungi and bacteria associated with decomposing leaf litter at different levels of nutrient availability. Aquatic Microbial Ecology 30, 149-157.

Gulis, V. \& Suberkropp, K. (2003c). Leaf litter decomposition and microbial activity in nutrient-enriched and unaltered reaches of a headwater stream. Freshwater Biology 48, 123-134.

Gulis, V., Suberkropp, K. \& Rosemond, A. D. (2008). Comparison of fungal activities on wood and leaf litter in unaltered and nutrient-enriched headwater streams. Applied and Environmental Microbiology 74, 1094-1101.

*Gunasekera, S. A., Webster, J. \& LegG, C. J. (1983). Effect of nitrate and phosphate on weight loss of pine and oak wood caused by aquatic and aero-aquatic hyphomycetes. Transactions of the British Mycological Society $\mathbf{8 0}$, 507-514.

Hagen, E. M., Webster, J. R. \& Benfield, E. F. (2006). Are leaf breakdown rates a useful measure of stream integrity along an agricultural landuse gradient? Journal North American Benthological Society 25, 330-343.

Hedges, L. V., Gurevitch, J. \& Curtis, P. S. (1999). The meta-analysis of response ratios in experimental ecology. Ecology 80, 1150-1156.

Hieber, M. \& Gessner, M. O. (2002). Contribution of stream detrivores, fungi, and bacteria to leaf breakdown based on biomass estimates. Ecology 83, 1026-1038.

*Hladyz, S., Tiegs, S., Gessner, M. O., Giller, P. S., Risnoveanu, G., Preda, E., Nistorescu, M., Schindler, M. \& Woodward, G. (2010). Leaf-litter breakdown in pasture and deciduous woodland streams: a comparison among three European regions. Freshwater Biology 55, 1916-1929.

Howarth, R. W. \& Fisher, S. G. (1976). Carbon, nitrogen, and phosphorus dynamics during leaf decay in nutrient enriched stream microecosystems. Freshwater Biology 6, 221-228.

*Huryn, A. D., Butz Huryn, V. M., Arbuckle, C. J. \& Tsomides, L. (2002) Catchment land-use, macroinvertebrates and detritus processing in headwater streams: taxonomic richness versus function. Freshwater Biology 47, $401-415$.

Irons, J. G., Oswood, M. W., Stout, R. J. \& Pringle, C. M. (1994). Latitudinal patterns in leaf litter breakdown: is temperature really important? Freshwater Biology 32, 401-411.

*Jenkins, C. C. \& Suberkropp, K. (1995). The influence of water chemistry on the enzymatic degradation of leaves in streams. Freshwater Biology 33, 245-253.

KNORR, M., Frey, S. D. \& Curtis, P. S. (2005). Nitrogen additions and litter decomposition: a meta-analysis. Ecology 86, 3252-3257.

Lajeunesse, M. J. (2013). Recovering missing or partial data from studies: a survey of conversions and imputations for meta-analysis. In Handbook of Meta-Analysis in Ecology and Evolution (eds J. Koricheva, J. Gurevitch and K. Mengersen), pp. 195-206 Princeton University Press, Princeton and London.

Lecerf, A. \& Chauvet, E. (2008a). Diversity and functions of leaf-decaying fungi in human-altered streams. Freshwater Biology 53, 1658-1672.

LeCERF, A. \& CHAUvet, E. (2008b). Intraspecific variability in leaf traits strongly affects alder leaf decomposition in a stream. Basic and Applied Ecology $\mathbf{9}$, 598-605.

Lecerf, A., Usseglio-Polatera, P., Charcosset, J.-Y., Bracht, B. \& Chauvet, E. (2006). Assessment of functional integrity of eutrophic streams using litter breakdown and benthic macroinvertebrates. Archiv für Hydrobiologie $\mathbf{1 6 5}$ $105-126$.

Leimu, R. \& Koricheva, J. (2004). Cumulative meta-analysis: a new tool for detection of temporal trends and publication bias in ecology. Proceedings of the Royal Society of London Series B 271, 1961-1966. 
LI, J. J.-H. (2011). The role of elevated dissolved versus foliar nitrogen on leaf litter processing in stream ecosystems. Masters Thesis: University of Maryland.

*Magbanua, F. S., Townsend, C. R., Blackwell, G. L., Phillips, N. \& Matthaei, C. D. (2010). Responses of stream macroinvertebrates and ecosvstem function to conventional, integrated and organic farming. Journal of Applied Ecology 47, 1014-1025.

Matthaei, C. D., Piggott, J. J. \& Townsend, C. R. (2010). Multiple stressors in agricultural streams: interactions among sediment addition, nutrient enrichment and water abstraction. Journal of Applied Ecology 47, 639-649.

McKie, B. G., Schindler, M., Gessner, M. O. \& MalmQvist, B. (2009). Placing biodiversity and ecosystem functioning in context: environmental perturbations and the effects of species richness in a stream field experiment. Oecologia 160, 757-770

*McTammany, M. E. (2004). Recovery of southern Appalachian streams from historical agriculture. PhD Thesis: Virginia Polytechnic Institute and State University.

* McTammany, M. E., Benfield, E. F. \& Webster, J. R. (2008). Effects of agriculture on wood breakdown and biofilm respiration in southern Appalachian streams. Freshwater Biology 53, 842-854.

Medeiros, A. O., Pascoal, C. \& Graça, M. A. S. (2009). Diversity and activity of aquatic fungi under low oxygen conditions. Freshwater Biology 54, 142-149.

Melillo, J. M., Naiman, R. J., Aber, J. D. \& Linkins, A. E. (1984). Factors controlling mass loss and nitrogen dynamics plant litter decaying in northern streams. Bulletin of Marine Sciences 35, 341-356.

*Menéndez, M., Descals, E., Riera, T. \& Moya, O. (2011). Leaf litter breakdown in Mediterranean streams: effect of dissolved inorganic nutrients. Hydrobiologia 669, 143-155.

Mesquita, A., Pascoal, C. \& Cássio, F. (2007). Assessing effects of eutrophication in streams based on breakdown of eucalyptus leaves. Fundamental and Applied Limnology 168, 221-230.

*Meyer, J. L. \& Johnson, C. (1983). The influence of elevated nitrate concentration on rate of leaf decomposition in a stream. Freshwater Biology 13, 177-183.

Molinero, J., Pozo, J. \& GonzÁlez, E. (1996). Litter breakdown in streams of the Agüera catchment: influence of dissolved nutrients and land use. Freshwater Biology 36, 745-756.

Murdoch, P. S., Baron, J. \& Miller, T. L. (2000). Potential effects of climate change on surface-water quality in North America. Journal of the American Water Resources Association 36, 347-366.

*Newbold, J. D., Elwood, J. W., Schulze, M. S., Stark, R. W. \& Barmeier, J. C. (1983). Continuous ammonium enriched of a woodland stream: uptake kinetics, leaf decomposition, and nitrification. Freshwater Biology 13, $193-204$.

Niyogi, D. K., Simon, K. S. \& Townsend, C. R. (2003). Breakdown of tussock grass in streams along a gradient of agricultural development in New Zealand. Freshwater Biology 48, 1698-1708.

Ostrofsky, M. L. (1997). Relationship between chemical characteristics of autumn-shed leaves and aquatic processing rates. Journal of the North American Benthological Society 16, 750-759.

* Pascoal, C. (2004). Microorganisms overwhelm invertebrates in control ling leaf litter breakdown in a polluted river. PhD Thesis: University of Minho.

Pascoal, C. \& Cássio, F. (2004). Contribution of fungi and bacteria to leaf litter decomposition in a polluted river. Applied Environmental Microbiology 70, $5266-5273$

*Pascoal, C., CÁssio, F. \& Gomes, P. (2001). Leaf breakdown rates: a measure of water quality? International Review of Hydrobiology 68, 407-416.

* Pascoal, C., Cássio, F. \& Marvanová, L. (2005). Anthropogenic stress may affect aquatic hyphomycete diversity more than leaf decomposition in a low-order stream. Archiv für Hydrobiologie 162, 481-496.

Pascoal, C., Pinho, M., Cássio, F. \& Gomes, P. (2003). Assessing structural and functional ecosystem condition using leaf breakdown: studies on a polluted river. Freshwater Biology 48, 2033-2044.

*Paul, M. J., Meyer, J. L. \& Couch, C. A. (2006). Leaf breakdown in streams differing in catchment land use. Freshwater Biology 51, 1684-1695.

*Pearson, R. G. \& Connolly, N. M. (2000). Nutrient enhancement, food quality and community dynamics in a tropical rainforest stream. Freshwater Biology 43, 31-42.

* Pérez, J. (2010). Descomposición de hojorasca en ríos de cabecera: variabilidade natural y evaluación de impactos. PhD Thesis: University of the Basque Country.

*Pérez, J., Menéndez, M., Larrañaga, S. \& Pozo, J. (2011). Inter- and intra-regional variability of leaf litter breakdown in reference headwater streams on Northern Spain: Atlantic versus Mediterranean streams. Interna tional Review of Hydrobiology 96, 105-117.

Peterson, B. J., Deegan, L., Helfrich, J., Hobbie, J. E., Hullar, M., Moller, B., Ford, T. E., Hershey, A., Hiltner, A., Kipphut, G., Lock, M. A., Fiebig, D. M., McKinley, V., Miller, M. C., Vestal, J. R., Ventullo, R. \& Volk, G. (1993). Biological responses of a tundra river to fertilization. Ecology 74, $653-672$.
Piggott, J. J., Lange, K., Townsend, C. R. \& Matthaei, C. D. (2012). Multiple stressors in agricultural streams: a mesocosm study of interactions among raised water temperature, sediment addition and nutrient enrichment. PLoS One 7, e49873.

Piscart, C., Genoel, R., Doledec, S., Chauvet, E. \& Marmonier, P. (2009). Effects of intense agricutural practices on heterotrophic processes in streams. Environmental Pollution 157, 1011-1018.

Piscart, C., Navel, S., Maazouzi, C., Montullle, B., Cornut, J., Mermillod-Blondin, F., Chatelliers, M. C., Somin, L. \& Marmonier, P. (2011). Leaf litter recycling in benthic and hyporheic layers in agricultural streams with different types of land use. Science of the Total Environment 409 $4373-4380$

*Pozo, J., Basaguren, A., Elosegui, A., Molinero, J., Fabre, E. \& Chauvet, E. (1998). Afforestation with Eucalyptus globulus and leaf litter decomposition in streams of northern Spain. Hydrobiologia 373-374, 101-109.

*Pozo, J., Casa, J., Menéndez, M., Mollá, S., Arostegui, I., Basaguren, A., Casado, C., Descals, E., García-Avilés, J., González, J. M., Larrañaga, A., López, E., Lusi, M., Moya, O., Pérez, J., Riera, T., Boblas, N. \& Salinas, M. J (2011). Leaf-litter decomposition in headwater streams: a comparison on the process among four climatic regions. Journal of the North American Benthological Society 30, 935-950.

*Rambo, C., Barnieri, R. P. \& Hepp, L. U. (2007). Transformaçoes de matéria orgânica de detrito foliar de Eugenia uniflora L. em condições de laboratório. Perspectiva Erechim 31, 45-52.

Rasmussen, J. J., Wiberg-Larsen, P., Baattrup-Pedersen, A., Monberg, R. J. \& KronvanG, B. (2012). Impacts of pesticides and natural stressors on leaf litter decomposition in agricultural streams. Science of the Total Environment 416, 148-155.

*Raviraja, N. S., Nikolcheva, L. G. \& Bärlocher, F. (2006). Fungal growth and leaf decomposition are affected by amount and type of inoculum and by external nutrients. Sydowia 58, 91-104.

Rockström, J., Steffen, W., Noone, K., Persson, A., Chapin, F. S., Lambin, E. F., Lenton, T. M., Scheffer, M., Folke, C., Schellnhuber, H. J., Nykvist, B., Wit, C. A., Hughes, T., Leeuw, S., Rodhe, H., Sörlin, S., Snyder, P. K., Costanza, R., Svedin, U., Falkenmark, M., Karlberg, L., Correl, R. W., Fabry, V. J., Hansen, J., Walker, B., Liverman, D., Richardson, K., Crutzen, P. \& Foley, J. A. (2009). A safe operating space for humanity. Nature 461, 472-475.

*Rosemond, A. D., Pringle, C. M., Ramírez, A. \& Paul, M. J. (2001). A test of top-down and bottom-up control in a detritus-based food web. Ecology $\mathbf{8 2}$, $2279-2293$

Rosemond, A. D., Pringle, C. M., Ramírez, A., Paul, M. J. \& Meyer, J. L. (2002). Landscape variation in phosphorus concentration and effects on detritus-based tropical streams. Limnology and Oceanography 47, $278-289$

*Rosemond, A. D., Swan, C. M., Kominoski, J. S. \& Dye, S. E. (2010). Non-additive effects of litter mixing are suppressed in a nutrient-enriched stream. Oikos 119, 326-336.

*Royer, T., Monaghan, M. T. \& Minshall, W. (1999). Processing of native and exotic leaf litter in two Idaho (U.S.A) streams. Hydrobiologia 400, $123-128$

RStudio (2012). RStudio: integrated development environment for $R$ (Version 2.15.2) (Computer software). Boston. Available at http://www.rstudio.com/ Accessed 5.2 .2013 .

Schäfer, R. B., Caquet, T., Simmes, K., Mueller, R., Lagadic, L. \& Liess, M. (2007). Effects of pesticides on community structure and ecosystem functions in agricultural streams of three biogeographical regions in Europe. Science of the Total Environment 382, 272-285.

Schindler, M. H. \& Gessner, M. O. (2009). Functional leaf traits and biodiversity effects on litter decomposition in a stream. Ecology 90, 1641-1649.

Shaftel, R. S., King, R. S. \& BACK, J. A. (2011). Breakdown rates, nutrient concentrations, and macroinvertebrate colonization of bluejoint grass litter in headwater streams on the Kenai Peninsula, Alaska. Journal of the North American Benthological Society 30, 386-398.

*Silva-Júnior, E. F. \& Moulton, T. P. (2011). Ecosystem functioning and community structure as indicators for assessing environmental impacts: leaf processing and macroinvertebrates in Atlantic forest streams. International Review of Hydrobiology 96, 656-666.

Spänhoff, B., Augspurger, C. \& Kuesel, K. (2007a). Comparing field and laboratory breakdown rates of coarse particulate organic matter: sediment dynamics mask the impacts of dissolved nutrients on CPOM mass loss in streams. Aquatic Sciences 69, 495-502.

Spänhoff, B., Bischof, R., Böhme, A., Lorenz, S., Neumeister, K., Nöthlich, A. \& KÜSEL, K. (2007b). Assessing the impact of effluents from modern wastewater treatment plant on breakdown of coarse particulate organic matter and benthic macroinvertebrates in a lowland river. Water, Air, E Soil Pollution $180,119-129$ 
*Sridhar, K. R. \& Bärlocher, F. (2000). Initial colonization, nutrient supply, and fungal activity on leaves decaying in streams. Applied and Environmental Microbiology 66, 1114-1119.

*Sridhar, K. R., Duarte, S., Cássio, F. \& Pascoal, C. (2009). The role of early fungal colonizers in leaf-litter decomposition in Portuguese streams impacted by agricultural runoff. International Review of Hydrobiology 94, 399-409.

*STallcup, L. A. (2004). Effect of water chemistry and leaf species on leaf breakdown in neotropical headwater streams. Masters Thesis: University of Georgia.

*Stallcup, L. A., Ardón, M. \& Pringle, C. M. (2006). Does nitrogen become limiting under high-P conditions in detritus-based tropical streams? Freshwater Biology 51, 1515-1526.

Stelzer, R. S., Heffernan, J. \& Likens, G. E. (2003). The influence of dissolved nutrients and particulate organic matter quality on microbial respiration and biomass in a forest stream. Freshwater Biology 48, 1925-1937.

*Suberkropp, K. (1991). Relationships between growth and sporulation of aquatic hyphomycetes on decomposing leaf litter. Mycological Research 95, $843-850$.

*Suberkropp, K. (1995). The influence of nutrients on fungal growth, productivity, and sporulation during leaf breakdown in streams. Canadian Journal of Botany 73, 1361-1369.

SubERKRopp, K. (1998). Effect of dissolved nutrients on two aquatic hyphomycetes growing on leaf litter. Mycological Research 102, 998-1002.

Suberkropp, K. \& Chauvet, E. (1995). Regulation of leaf breakdown by fungi in streams: influences of water chemistry. Ecology 76, 1433-1445.

*Thomson, F. J. (2004). The impacts of nutrient enrichment and sediment addition on leaf decomposition and algal accrual in Otago streams. Masters Thesis: University of Otago.

*Tonin, A. M. \& Hepr, L. U. (2011). Effects of nitrate enrichment on leaf litter decomposition. Acta Limnologica Braziliensia 23, 1-9.

Triska, F. J. \& Sedell, J. R. (1976). Decomposition of four species of leaf litter in response to nitrate manipulation. Ecology 57, 783-792.

ViechtbaueR, W. (2010). Conducting meta-analysis in R with the metafor package. Journal of Statistical Software 36, 1-48.

Vitousek, P. M., Aber, J. D., Howarth, R. W., Likens, G. E., Matson, P. A., Schindler, D. W., Schlesinger, W. H. \& Tilman, D. G. (1997). Human alteration of the global nitrogen cycle: sources and consequences. Ecological Applications 7, 737-750.

Wallace, J. B., Eggert, S. L., Meyer, J. L. \& Webster, J. R. (1997). Multiple trophic levels of a forest stream linked to terrestrial litter inputs. Science 277, $102-104$.

WARD, G. W. \& AumEn, N. G. (1986). Woody debris as a source of fine particulate organic matter in coniferous forest stream ecosystems. Canadian Journal of Fisheries and Aquatic Sciences 43, 1635-1642.

*Weyers, H. S. \& Suberkropp, K. (1996). Fungal and bacterial production during the breakdown of yellow poplar leaves in 2 streams. Journal of the North American Benthological Society 15, 408-420.

Woodward, G., Gessner, M. O., Giller, P. S., Gulis, V., Hladyz, S., Lecerf, A., Malmovist, B., McKie, B. G., Tiegs, S. D., Cariss, H., Dobson, M., Elosegi, A., Ferreira, V., Graça, M. A. S., Fleituch, T., Lacoursière, J., Nistorescu, M., Pozo, J., Risnoveanu, G., Schindler, M., Vadineanu, A., Vought, L. B.-M. \& Chauvet, E. (2012). Continental-scale effects of nutrient pollution on stream ecosystem functioning. Science 336, 1438-1440.

Woodward, G., Perkins, D. M. \& Brown, L. E. (2010). Climate change and freshwater ecosystems: impacts across multiple levels of organization. Philosophical Transactions of the Royal Society of London B 365, 2093-2106.

*Young, R. G. (2007). A trial of wood decomposition rates as an ecological assessment tool in large rivers. Prepared for West Coast Regional Council. Cawthron Report No. 1339. Nelson, Cawthron Institute, New Zealand.

Young, R. G. \& Collier, K. J. (2009). Contrasting responses to catchment modifications among a range of functional and structural indicators of river ecosystem health. Freshwater Biology 54, 2155-2170.

*Young, R. G., Huryn, A. D. \& Townsend, C. R. (1994). Effects of agricultural development on processing of tussock leaf litter in high country New Zealand streams. Freshwater Biology 32, 413-427.

Young, R. G., Matthaei, C. D. \& Townsend, C. R. (2008). Organic matter breakdown and ecosystem metabolism: functional indicators for assessing river ecosystem health. Journal of the North American Benthological Society 27, $605-625$.

\section{SUPPORTING INFORMATION}

Additional supporting information may be found in the online version of this article.

Appendix S1. List of primary studies included in this review.

Fig. S1. Geographic distribution of case studies included in the analyses.

Fig. S2. Effects of mean dissolved inorganic nitrogen (DIN) and soluble reactive phosphorus (SRP) concentrations in reference conditions (REF), and magnitude of the increase in DIN and SRP concentrations in nutrient-enriched conditions (NUT) versus REF, on litter decomposition $(\operatorname{lnR})$, for laboratory studies.

Fig. S3. Effects of mean dissolved inorganic nitrogen (DIN) and soluble reactive phosphorus (SRP) concentrations in reference conditions (REF), and magnitude of the increase in DIN and SRP concentrations in nutrient-enriched conditions (NUT) versus REF, on litter decomposition ( $\ln R)$, in manipulative field studies.

Table S1. Data matrix used in this review.

Table S2. Identification, levels and description of moderator variables used in this review.

Table S3. Summary table for subgroup analyses considering the initial dataset.

Table S4. Relationship between effect sizes $(\ln R)$ and mean dissolved inorganic nitrogen (DIN) and soluble reactive phosphorus (SRP) concentrations in reference conditions (REF), and magnitude of the increase in DIN concentration and SRP concentration in nutrient-enriched conditions (NUT) versus REF, for laboratory, correlative and manipulative studies.

Table S5. Summary table for subgroup analyses considering the dataset without Bärlocher \& Corkum (2003) and Woodward et al. (2012).

Table S6. Summary table for subgroup analyses considering the dataset without unpublished cases (grey literature).

Table S7. Summary table for subgroup analyses considering the dataset without cases for which $k$ day $^{-1}$ or S.D. values were not reported in the primary studies or provided by the authors.

Table S8. Summary table for subgroup analyses considering a mean effect size per study. 